\title{
At the Intersection of Cardiology and Oncology: TGF $\beta$ as a Clinically Translatable Therapy for TNBC Treatment and as a Major Regulator of Post-Chemotherapy Cardiomyopathy
}

\author{
Andrew Sulaiman ${ }^{1 ¥}$, Jason Chambers ${ }^{2}$, Sai Charan Chilumula ${ }^{1}$, Vishak Vinod ${ }^{1}$, Rohith Kandunuri ${ }^{1}$, Sarah \\ McGarry $^{3}$ and Sung Kim ${ }^{1}$ \\ 1 Department of Basic Science, Kansas City University, 1750 Independence Ave, Kansas City, MO 64106, USA \\ 2 Western University, Schulich School of Medicine, London, Canada \\ 3 Children's Mercy Hospital Kansas City, 2401 Gillham Rd, Kansas City, MO, 64108, USA \\ ${ }^{¥}$ Correspondence Andrew Sulaiman (asula097@uottawa.ca) Tel: 816-726-2293
}

Simple Summary: Specific/targeted therapies have been shown to be effective in the treatment of certain cancers. Unfortunately, there currently is no specific therapy for the treatment of triple negative breast cancer (TNBC) which is attributed to why this subtype of breast cancer is associated with reduced patient prognosis. While there is an immense focus on development on new therapies the issue of cardiotoxicity following chemotherapeutic treatment is commonly overlooked despite its role as a leading cause of mortality in cancer survivors. This review aims to discuss the connection of TGF- $\beta$ signaling, and its role in modulating cardiac fibrosis and remodeling as well as its role in TNBC tumor progression, cancer stem cell enrichment, chemoresistance and relapse. Together we highlight the modulation of TGF- $\beta$ as a method to target two of the greatest causes of morbidity and mortality in breast cancer patients.

\begin{abstract}
Triple-negative breast cancer (TNBC) is a subtype of breast cancer that disproportionally accounts for the majority of breast cancer-related deaths due to the lack of specific targets for effective treatments. While there is immense focus on the development of novel therapies for TNBC treatment, a persistent and critical issue is the rate of heart failure and cardiomyopathy which is a leading cause of mortality and morbidity amongst cancer survivors. In this review, we highlight mechanisms of cardiotoxicity post-chemotherapeutic exposure, assess how this is assessed clinically and highlight the transforming growth factor-beta family (TGF- $\beta$ ) pathway and discuss its role as a mediator of cardiomyopathy. We highlight recent findings demonstrating TGF- $\beta$ inhibition as a potent method to prevent cardiac remodeling, fibrosis and cardiomyopathy. We describe how dysregulation of the TGF- $\beta$ pathway is associated with negative patient outcomes across 32 types of cancer including TNBC. We then highlight how TGF- $\beta$ modulation may be a potent method to target mesenchymal (CD44+/CD24-) and epithelial (ALDH $\left.{ }^{\text {high }}\right)$ cancer stem cell (CSC) populations in TNBC models. CSCs are associated with tumorigenesis, metastasis, relapse, resistance, and diminished patient prognosis; however, due to plasticity and differential regulation these populations remain difficult to target and persist as a major barrier barring successful therapy. TGF- $\beta$ inhibition represents an intersection of two fields: cardiology and oncology. Through inhibiting cardiomyopathy, cardiac damage and heart failure may be prevented and through CSC targeting, patient prognosis may be improved. Together, both approaches, if successfully implemented would target the two greatest causes of cancer-related morbidity in patients and potentially lead to a breakthrough therapy.
\end{abstract}

Keywords: TNBC TGF- $\beta$; Cardiology; Oncology; CSC 
Citation: Lastname, F.; Lastname, F.; Last-name, F. Title. Cancers 2021, 13, x. https://doi.org/10.3390/xxxxx Academic Editor: Firstname Lastname Received: date Accepted: date Published: date

Publisher's Note: MDPI stays neutral with regard to jurisdictional claims in published maps and institutional affiliations.

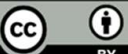

Copyright: @ 2020 by the authors. Submitted for possible open access publication under the terms and conditions of the Creative Commons Attribution (CC BY) license (http://creativecommons.org/licenses /by/4.0/).

\subsection{Introduction}

Breast cancer is the most frequent cancer affecting women and accounted for over 2 million breast cancer diagnoses and approximately 600,000 related mortalities in 2018[1]. TNBC only accounts for the minority of breast cancer incidences (15-20\%); however, TNBC is disproportionally associated with reduced patient prognosis compared to the other breast cancer subtypes[2,3]. TNBC in contrast with other breast cancer subtypes lacks expression of the estrogen receptor, progesterone receptor and HER-2. The presence of these receptors are associated with the usage of specific therapies; thus non-specific chemotherapies and radiotherapies are mainstays for the treatment of TNBC which overall is associated with reduced patient prognosis.

As such, there is immense focus on the development of targeted therapies to target TNBC. However, a critical issue garnering increased attention in preclinical research is the high incidence of cardiotoxicity following therapy leading to increased rates of heart failure and cardiomyopathy[4]. CVD and its related complications is a leading cause of morbidity and mortality in cancer survivors[5]. In a observational study, Patnaik et al demonstrated in 63,566 breast cancer patients, that while there were increased adjusted relative hazards of comorbidities such as cardiovascular disease, COPD and diabetes; it was found that cardiovascular disease was the primary cause of death amongst the patients $(15.9 \%)$ exceeding mortality due to breast cancer $(15.1 \%)[6]$.

Moreover, Bardia et al demonstrated in a clinical trial using a 10-year recurrence risk prediction model in breast cancer patients with early stage breast cancer (stage I-III with $67.5 \%$ having stage I) which calculated CVD and breast cancer recurrence risk [7]. It was found that the risk of a CVD event exceeded the risk of breast cancer relapse in $37 \%$ of the patients and $43 \%$ possessed a risk equal to that of breast cancer recurrence[7]. These studies highlight that not only is the development of therapeutics for primary tumor management important for patient prognosis, but that the cardiovascular health of the patient must be protected due to sensitivity following chemotherapy treatment.

To highlight this point, a recent study by Sturgeon et al, 3,234,256 US cancer survivors from the year 1973-2012 were assessed and mortality ratios stemming from CVD (consisting of a grouping of heart disease, hypertension, atherosclerosis, cerebrovascular disease, aortic aneurysm or aortic dissection) and cancer related causes were assessed[8]. The patients were separated by cancer type and CVD mortality was found to highly elevated in patients diagnosed with breast, prostate or bladder cancer (together accounting for $61 \%$ of all CVD mortality) and also in patients diagnosed at an earlier age ( $<35$ years old)[8]. Importantly, this study identified that CVD is highly prevalent in breast cancer and that the risk of CVD mortality is continually elevated throughout the follow ups of the study and does not dissipate[8].

Due to the essential inclusion of cardiotoxic agents such as anthracyclines, taxanes and antimetabolites for the treatment of breast cancer combined with the CVD issues plaguing patients post-chemotherapeutically there is a drastic need for cardio-oncology research into mechanisms promoting chemotherapy induced cardiotoxicity and methods to alleviate this process. This review will discuss mechanisms of chemotherapy induced cardiomyopathy in TNBC patients and also highlight TGF- $\beta$ signaling as an emerging pathway of therapeutic interest for the prevention of chemotherapy induced cardiotoxic effects. Additionally, this review will highlight the anti-tumorigenic properties of TGF- $\beta$ modulation in targeting the TNBC bulk tumor and its CSC populations. Clinically translatable mediators of TGF- $\beta$ signaling involved in breast cancer and cardiac disease related clinical trials will be described and listed for future investigation. 


\subsection{Post-Chemotherapeutic Cardiomyopathy}

Due to the aforementioned lack of specific cellular targeting in TNBC treatment, there is a strong reliance on standard cytotoxic chemotherapeutic agents in clinical practice.[9] These regimens often involve the use of anthracycline or taxane class chemotherapeutic agents.[10] Unfortunately, chemotherapy often induces very severe side effects, with cardiotoxicity at the forefront of dose limiting toxicity.[11]

Cardiotoxicity is a broad term which includes both early and late onset forms as well as effects ranging from subclinical impairment of cardiac function to cardiac death.[12] Early onset, also called "acute"/"subacute" cardiotoxicity develops immediately after chemotherapeutic infusion or up to 2-4 weeks after completion and is typically characterized by reversible arrhythmias, abnormalities in ventricular repolarization, prolongation of the QT interval, acute coronary syndrome, pericarditis/myocarditis-like syndromes or altered myocardial function.[13] Late onset cardiotoxicity can be divided into either early-chronic or late-chronic subtypes. Early chronic cardiotoxicity occurs within 1 year after termination of chemotherapy while late-chronic cardiotoxicity occurs more than 1 year after termination.[14] Late-onset cardiotoxicity can result in systolic/diastolic left ventricular dysfunction that leads to congestive cardiomyopathy which can transition towards cardiac death.[14] Additionally, cardiomyopathy can be classified into two subtypes: type I (caused by cardiomyocyte death and is irreversible) and type II (caused by cardiomyocyte impairment of cardiac function and is reversible).[15] This concept was originally proposed by Ewer et al and these subtypes can differentiate the effects of various chemotherapeutic agents; for example, doxorubicin (an anthracycline class chemotherapeutic) induces type I cardiotoxicity while the biologic trastuzumab (an anti HER-2 chemotherapeutic agent) induces type II cardiotoxicity.[15]

\subsection{Anthracycline and Taxane Mechanisms of Cardiotoxicity}

Doxorubicin, an anthracycline, is one of the most frequently prescribed chemotherapeutic agent for the treatment of TNBC. The toxicity of doxorubicin on cardiac tissue is mediated through multifactorial mechanisms which remain convoluted. One commonly proposed mechanism is that anthracycline agents such as doxorubicin are prone to the generation of reactive oxygen species (ROS) during their metabolism.[11] Specifically, the univalent reduction of the anthracycline class quinone moiety by mitochondrial complex I in the electron transport chain (ETC) results in the formation of semiquinone radicals which rapidly undergo auto-oxidation to form superoxide anions (O2-), thereby also regenerating the quinone moiety. $[16,17]$ This cycle can then continue under aerobic conditions, producing additional ROS. This process may shed light on the correlation between anthracycline class chemotherapeutics and the induction of cardiotoxicity as the cardiomyocytes experience large demand for ATP produced by ETC, and therefore have a greater density of mitochondria (and subsequently complex I) than other cell types[18]. The high rate of ROS production in the mitochondrion of the cardiomyocyte can then interfere with iron reduction, damaging the cells via ROS mediated reactions which result in the formation of reactive nitrogen species leading to mitochondrial/cardiomyocyte dysfunction which ultimately promotes apoptosis [19-21].

Another proposed mechanism for the cardiotoxicity of anthracyclines is via its intended anti-tumor mechanism of DNA-topioisomerase2 (Top2) intercalation, wherein the anthracycline forms a Top2-doxorubicin-DNA ternary complex. In humans Top2 is expressed as the isoenzymes Top $2 \alpha$ and Top $2 \beta$, with the former expressed in proliferative cells (including cancer cells) and the latter in quiescent cells[22]. Top2 $\beta$ positive malignant cells demonstrate ternary complex formation upon anthracycline therapy promoting the inhibition of DNA replication leading to G1/G2 arrest and apoptosis in cancerous cells. 
Unfortunately, Top2 $\beta$ is also the primary form expressed in adult cardiac tissue promoting anthracycline binding and cardiotoxicity resulting in mitochondrial and cellular dysfunction.[23],[24]

Paclitaxel (a taxane) is another commonly used chemotherapeutic agent in the treatment of breast cancer, especially in anthracycline-resistant breast cancer.[25] Although it was thought that taxanes have negligible cardiotoxicity when compared to anthracyclines, phase I and II clinical trials revealed acute cardiac reactions upon paclitaxel infusion such as: cardiac rhythm disturbances, atrioventricular conduction abnormalities, sinus bradycardia and ventricular tachycardia [26],[27]. Importantly, the majority of cardiac disturbances were not associated with clinical symptoms and were found incidentally during cardiac monitoring. Moreover, these cardiac issues were common in taxane treated patients with $29 \%$ of patients having asymptomatic bradycardia when administered the maximal tolerable dose of taxane therapy $(110-250 \mathrm{mg} / \mathrm{m} 2)$ [28]. One proposed mechanism for taxane cardiotoxicity is the mediated not by the taxane agent itself but rather through its formulation vehicle, Cremophor EL (a vehicle to enhance the solubility). It has been proposed that Cremophor EL induces massive histamine release causing acute cardiovascular reactions.[29] Interestingly, taxanes such as paclitaxel are often used in combination with anthracyclines; however, it was found in clinical trials that the combination produced unacceptably high rates of heart failure (18\% of patients)[30]. This is thought to be due to pharmacokinetic interference, where paclitaxel interferes with the clearance of doxorubicin possibly through competition for biliary clearance promoting cardiotoxicity.[31]

\subsection{Clinical assessment of cardiotoxicity}

The severity of cardiomyopathy is important not only for determining therapeutic course but also for the manifestations of CVD later in life, especially in regards to pediatric populations who were administered chemotherapeutic agents. The gold standard for anthracycline class cardiotoxicity determination is a cardiac biopsy; however, due to the impracticality of this as a clinical assessment it is not typically considered. Rather, cardiac imaging can be used to monitor cardiac deterioration, where the left ventricle ejection fraction (LVEF) is used to track progression. LVEF can be determined via TC-99 Multiple Gated Acquisition Scan (MUGA), also called radionuclide ventriculography[32,33]. Current guidelines place cardiotoxicity as one or more of the following: 1) Reduction of LVEF, either globally or more within the septum. 2) The onset of symptoms associated with heart failure. 3) A reduction of $>5 \%$ to $<55 \%$ in regards to the ejection fraction (EF) alongside symptoms of heart failure, or a $>10 \%$ to $<55 \%$ decline in EF without symptoms of heart failure[34,35]. It's thought that through patient monitoring, cardiotoxic effects of anthracycline therapy can be discovered early and its effects minimized. Research by Swain et al however challenge this notion via demonstrating that doxorubicin-related CHF may occur at a lower dosage, at a greater frequency (26\% compared to the $7 \%$ at a cumulative dose of at $550 \mathrm{mg} / \mathrm{m} 2$ ) and outside guideline parameters[36]. These findings challenge LVEF tracking and highlight the importance in mitigating chemotherapy induced cardiotoxicity. In addition to this finding, radionuclide ventriculography emits a high dose of radiation and is relatively expensive, making it a poor choice for longitudinal cardiac monitoring.

In contrast, echocardiogram is a radiation free, cheap, and readily available alternative for measurements of LVEF as compared to MUGA; however, it was found by Hoffmann et al that unenhanced echocardiography resulted in a slight underestimation of EF as compared to radionuclide ventriculography or MRI assessment.[37]. This disappointing result was however improved upon the use of contrast, where contrasted echocardiography was found to be comparable to MRI and even exceed the capabilities of radionuclide 
ventriculography [37]. Additionally, echocardiography can evaluate for adverse structural effects, such as valvular disease or pericardial constriction[38,39].

Cardiovascular magnetic resonance imaging (CMR) is another imaging technique for the evaluation of cardiomyopathies induced by cardiotoxic therapies which has the advantage of being radiation free[40]. CMR has the ability to detect subclinical cardiac dysfunction prior to detectable LVEF changes in addition to the ability to detect myocardial edema (a marker of myocardial injury). The high cost and low availability of CMR in contrast to echocardiography make it less widely utilized as a screening tool.[38]

The utilization of electrocardiogram (ECG) for cardiac monitoring circumvents the above problems associated with imaging and has the added benefit of being inexpensive and readily available. Horacek et al found statistically significant correlation between decreased QRS voltage, corrected QT interval (QTc) prolongation and left ventricular dysfunction as visualized by echocardiography[41]. ECG also has the added benefit of being able to correlate with malignant ventricular arrhythmias via QTc, an important indicator of acute cardiotoxicity[41]. Additionally, Fukumi et al found that signal-averaged ECG was able to detect acute and chronic cardiotoxicity from anthracycline chemotherapeutics at lower cumulative doses than echocardiography based imaging. Such a finding could allow for earlier insight into cardiac dysfunction[42].

Many well established biomarkers are used to investigate the cardiomyocyte damage. Not only can troponins serve as an indicator of damage, but their levels correlate with the clinical severity of the damage that occurs from the insult[43]. This allows for risk stratification during an infarct or other cardiac insults[44]. A study by Cardinale et al found that elevation in Troponin I in patients undergoing high dose chemotherapy (anthracyclines) preceded and was able to accurately predict the development of future cardiac dysfunction (via lowered LVEF)[45]. As the elevation of cardiac troponin I is a very specific and sensitive marker for cardiac damage and is one that many hospitals utilize in their practice its adoption into chemotherapy related cardiac monitoring remains a popular proposition[46]. Other markers of interest include natriuretic peptides such as Brain Natriuretic Peptide (BNP), its preprohormone and cleavage product (NT-proBNP) and Atrial Natriuretic Peptide (ANP). These substances serve to regulate blood pressure and circulating blood volume and are released from cardiomyocytes in response to atrial stretching/volume overload[47]. Similar to troponins, BNP may allow for the early detection of cardiotoxicity, although they may have the added advantage of being detectable for longer periods of time. While troponin was detectable within 4-15 hours until 10-14 days, natriuretic peptides were detectable within 24 hours and for as long as 2 years[48-52]. Routine assessment of patients exposed to chemotherapy with the detection methods described above would serve to identify early signs of CVD post-treatment allowing for increased opportunity to mitigate negative effects and increase prognosis in patients post therapy.

\subsection{TGF- $\beta$ Overview}

Extensive studies have shown that transforming growth factor beta (TGF- $\beta$ ) is a major mediator which modulates multiple cellular steps that promote cardiovascular disease, cardiac hypertrophy, arrhythmia, fibrosis and cardiac failure [53]. In brief, various proteins/conditions have been found to activate TGF- $\beta$ secretion [54]. Initially, TGF- $\beta$ ligand is bound by the TGF- $\beta$ binding protein which is activated via binding of $\alpha \mathrm{v}$ integrin to the prodomain of TGF- $\beta 1 / 2$ mediated by a myriad of conditions including myofibroblast induced contraction [55-57]. Activated TGF- $\beta$ signaling is primarily mediated via two distinctive downstream effectors: the SMAD pathway and the non-canonical pathway. SMAD signaling is mediated through activated TGF- $\beta$ interaction with type I (T $\beta$ RI) and type II receptor (T $\beta$ RII) via trans-phosphorylation of multiple serine/threonine residues 
of T $\beta$ RI GS domain [58]. The activated TGF- $\beta$ type I receptor then activates SMAD2 and SMAD3 via phosphorylation. Following SMAD2/3 activation, the complex trimerizes with SMAD4 forming the activated SMAD complex which translocate into the nucleus to regulate transcription for a variety of downstream effectors including the COL1A1/COL3A1 genes that facilitate production/deposition of collagens, plasminogen activator inhibitor1 that builds matrix, and connective tissue growth factor that upregulates the expression of fibronectin or heparan sulfate proteoglycans (HSPG) (Figure1) [59,61].

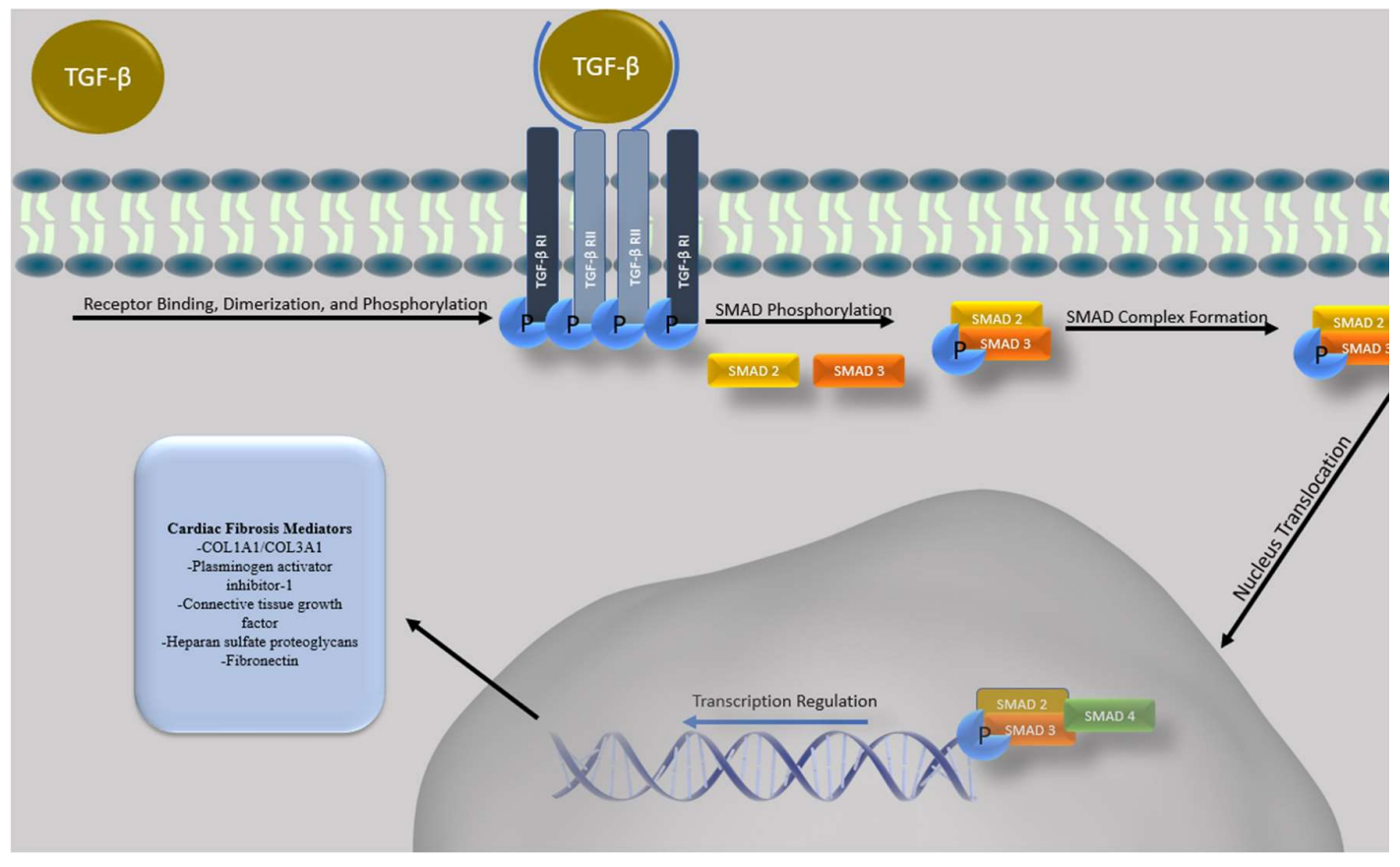

Figure 1: Overview of Conventional TGF- $\beta$ Signaling. A schematic overview of conventional (SMAD mediated) TGF- $\beta$ signaling occurring after TGF- $\beta$ ligand binding which leads to the activation of TGF- $\beta$ type II and TGF- $\beta$ type II receptor heteromeric complex which can induce the phosphorylation of SMAD2 and 3, promoting complex formation with co-SMAD (SMAD4). This trimeric complex can translocate into the nucleus and induce transcription of numerous genes including those involved in cardiac remodeling and fibrosis as well as cellular differentiation, survival, invasion and apoptosis.

SMAD-independent pathways are broadly referenced as non-canonical pathways and can mediate TGF- $\beta$ signaling independently or work in conjunction with SMAD-dependent pathways to facilitate/repress the TGF- $\beta$ pathway $[62,63]$. Amongst the various non-canonical mediated intercellular signals, mitogen activated protein (MAP) kinase is one of the mechanistic pathways which showed growing evidence of its roles in mediating TGF$\beta$ induced cardiac fibrosis [64]. Activated TGF- $\beta$ receptors can interact with TNF Receptor Associated Factor 6 (TRAF-6) to induce ubiquitination [62]. Subsequently, ubiquitinated TRAF- 6 recruits TGF- $\beta$ activated kinase (TAK-1). TAK- 1 activation consists of the kinase domain of TAK-1 forming a complex with TAK1-binding protein (TAB1). The active TAK1-TAB1 heterometric complex can then upregulate non-canonical mediating effectors such as MKK4/7 and MKK3/6 via phosphorylation [65]. Phosphorylated MMK4/7 upregulates the expression of JNK which in turn recruits transcriptional factor c-jun. Similarly, phosphorylated MMK3/6 can upregulate the expression of p38 which in turn increases the expression of ATF-2 [62,63]. These non-canonical pathways induce c-jun and ATF-2 cotranscription factors which can regulate the expression of SMAD dependent fibrosis via phosphorylation, signifying the intricate cellular interplays between the SMAD dependent and non-canonical induced fibrosis in cardiac models $[62,63,66]$. 


\subsection{TGF- $\beta$ as a Mediator of Cardiac Fibrosis and Remodeling}

Cardiac fibrosis is a hallmark response to injuries of the heart and its onset has been associated with myocardial infarction, ventricular remodeling, arrhythmia, dilated cardiomyopathy and heart failure [67-69]. Cardiac fibrosis is characterized by the differentiation of cardiac fibroblasts into myofibroblasts $[70,71]$. TGF- $\beta$ is a crucial mediator in the differentiation of myofibroblasts and resistance to apoptosis via activation of the Smad3 pathway which promotes $\alpha$-SMA (alpha-smooth muscle actin) transcription in fibroblasts and induces extracellular matrix protein deposition and myofibroblast differentiation[72-75].

Dobaczewski et al demonstrated via a closed-chest model of coronary occlusion/reperfusion to induce reperfused myocardial infarction in Smad3 null mice that ablation of SMAD-mediated signaling was associated with a reduction of $\alpha$-SMA transcription in fibroblasts. Furthermore, upon TGF $\beta 1$ stimulation, while wild-type mice demonstrated increased $\alpha$-SMA and fibrosis, Smad3 null mice did not, highlighting the association between TGF $\beta$-SMAD signaling and the cardiac fibrosis[73]. In another similar study, a closed-chest model of reperfused myocardial infarction in Smad3 null mice demonstrated that TGF- $\beta 1$ stimulation was associated with upregulation of procollagen III but not in Smad3-null mice, which indicates that TGF- $\beta$ mediated Smad3 signaling plays an important role in the extracellular matrix protein synthesis[76]. Using mice subjected to cardiac pressure overload stimulation via transverse aortic constriction surgery, Khalil et al showed that TGF- $\beta$ treated Smad3 and Smad2/3-deleted fibroblasts had a significant reduction in fibroblast marker genes (POSTN, COL1A1, and COL3A1) in primary cardiac fibroblasts, indicating that deletion of Smad3 from newly activated fibroblasts may significantly attenuate the cardiac fibrosis response[77].

Additionally, angiotensin II of the Renin-Angiotensin-Aldosterone System (RAAS) has been associated with the onset of cardiac fibrosis. Research has demonstrated the correlation between angiotensin II expression and TGF- $\beta$ expression in cardiac fibroblasts[78-80]. Wang et al stimulated mouse primary aorta vascular smooth muscle cells (VSMCs) with angiotensin II in vitro and demonstrated that angiotensin II can mediate Smad2/3 signaling pathway in a TGF- $\beta$ dependent manner[81]. Furthermore, Zhang et al demonstrated that chronic angiotensin II infusion upregulates human c-reactive protein (CRP) in CRP transgenic mice, leading to a 5-fold increase in serum CRP, a biomarker associated with cardiovascular diseases and events. As angiotensin II-induced cardiac TGF- $\beta 1$ expression and activation of the Smad signaling were enhanced in CRP transgenic mice as well this highlights that angiotensin II mediated activation of TGF- $\beta$ plays a pathogenic role in cardiac remodeling[82].

TGF- $\beta$ can also mediate non-canonical signaling to promote pathological cardiac remodeling via activation of TGF- $\beta$ Activated Kinase 1 (TAK1) as a delayed response to mechanical stress. Transgenic mice that expressed TAK1DN (a constitutive active form of TAK1) under the control of cardiac specific aMHC promoter (aMHC-TAK1DN) had a $46 \%$ increase in cardiac mass at 9-11 days after aortic banding and selective activation of p38 in myocardium at 9 days (up to 400\%). Hearts of mice 9-10 days old showed hypertrophied myocytes with hyperchromatic nuclei, interstitial fibrosis, and other signs seen in loadinduced hypertrophy and heart failure[83]. Constitutive overexpression of the human tumor suppressor A20 suppressed TAK-1 induced collagen synthesis and TAK-1 dependent Smad 2/3/4 activation in murine hearts, protecting against cardiac hypertrophy and fibrosis[84]. Thus, TGF- $\beta$ mediated TAK-1 activity plays an important role in myocardial hypertrophy and heart failure.

Thus, TGF- $\beta$ through SMAD dependent and independent signaling is associated with the onset of adverse cardiac pathologies and negative clinical outcomes making preclinical 
research into TGF- $\beta$ modulation for the treatment of cardiac disease as potential target for further clinical consideration. This is highlighted in a study by Laviades et al which demonstrated that hypertension and microalbuminuria in patients was associated with left ventricular hypertrophy and higher levels of serum TGF- $\beta 1$ compared to normotensive participants. In the same hypertensive patient group, treatment with Losartan (a clinically approved angiotensin II receptor antagonist with TGF- $\beta$ inhibitory activity) decreased TGF- $\beta 1$ levels in patients which correlated with a reduction of microalbuminuria and left ventricular hypertrophy [85]. To further highlight the importance of TGF- $\beta$ in cardiac function, using sequence specific oligonucleotide probing (SSOP), Holweg et al studied genomic DNA samples from heart transplant recipients and found that Leu $>$ Pro (codon 10) polymorphism in the TGFB1 gene is associated with end-stage heart failure caused by dilated cardiomyopathy[69]. Thus, TGF- $\beta$ through SMAD dependent and independent signaling is associated with the onset of adverse cardiac pathologies and negative clinical outcomes making preclinical research into this pathway for the treatment of cardiac disease an unmet medical need.

\subsection{TGF- $\beta$ Inhibition to Prevent Cardiomyopathy}

It has been demonstrated that TGF- $\beta$ exerts physiologic effects on embryonic development, cardiac development and cellular growth and it has been further highlighted that dysregulated TGF- $\beta$ signaling is associated with a host of unwanted pathologic conditions such as fibrosis, cardiac hypertrophy and inflammation [86-89]. Thus, modulation of TGF$\beta$ through pharmacologic agents may be of therapeutically benefit patients with postchemotherapy fibrosis, heart failure and cardiomyopathy.

Oliveira et al, demonstrated that GW788388 (a TGF- $\beta$ inhibitor specific for T $\beta R I / A L K 5$ ) can reduce cardiac fibrosis [90]. This was demonstrated through injecting Swiss mice with Trypanosoma Cruzi parasites to induce Chagas disease and cardiac fibrosis which was measured via fibronectin and collagen type I deposition [90]. It was found that this model induced substantial indications of cardiac fibrosis; however, upon treatment with GW788388, deposition of fibronectin and collagen type I was reduced in cardiomyocytes and cardiac electrical conduction was improved [90]. In a separate study by Ferreira et al, these results were repeated in a chronic Chagas in vivo mouse model consisting of C57BL/6 mice injected with Trypanosoma Cruzi and treated with GW788388 [91]. Mice receiving treatment demonstrated reduced fibrosis of cardiac tissue indicated by reduced levels of collagen type I and fibronectin deposition in cardiac tissue. Moreover, GW788388 inhibited TGF- $\beta / \mathrm{pSmad} 2 / 3$ expression and activity which was correlated with reduced CD3+ inflammatory lymphocyte cell migration into cardiac tissue [91]. Interestingly, these effects were correlated with increased stem cell antigen-1 (Sac-1+) cardiac cells following treatment. As Sca-1+ is a marker for cardiac stem cells it was suggested that TGF- $\beta$ inhibition can not only inhibit fibrosis but also promote the enrichment of cardiac stem cells which could promote cardiac recovery [91].

TGF- $\beta$ has also demonstrated translatability in the treatment of myocardial infarction (MI). Myocardial infarctions lead to cardiomyocyte death through ischemia, fibrosis and eventual heart failure. During a MI, there is a well-documented upregulation of TGF- $\beta$ isoforms which facilitate healing and repair $[87,92,93]$. This process however also leads to fibroblastic extracellular matrix protein deposition and an upregulation of TIMPs (Tissue inhibitors of metalloproteinases) which inhibits matrix degeneration and ultimately stimulates fibrosis [94]. Khalil et al highlights the importance of TGF- $\beta$ signaling in the fibrotic response via deletion of TGF- $\beta$ receptors TGF $\beta$ R1/2 and Smad3 in cardiac fibroblasts which reduced TGF- $\beta$-induced gel contraction indicating a disruption in myofibroblast differentiation. Moreover, a novel in vivo mouse model was used with Periostin-GFP reporter tracking of myofibroblasts of the heart in combination with TGF $\beta R 1 / 2, \operatorname{Smad} 2$, 
Smad3 and Smad2/3 knockouts [95]. This model then induced cardiac pressure overload via aortic constriction (an in vivo methodology to induce cardiac hypertrophy and heart failure) which found that deletion of Smad3, Smad2/3, or TGF $\beta R 1 / 2$ was able to inhibit cardiac fibrosis following aortic constriction [95]. Moreover, 12 weeks after aortic constriction TGF $\beta R 1 / 2$ knockout mice demonstrated reduced ventricular fractional shortening, preserved diastolic function and reduced cardiac hypertrophy highlighting the targeting of the TGF- $\beta$ pathway as a viable strategy to reduce cardiac fibrosis [95]. Importantly it was also found that the inhibition of $S \operatorname{mad} 2 / 3$ led to reduced fibroblast proliferation, differentiation and activity which correlated with a reduction of cardiac fibrosis although it did not lead to altered hypertrophy [95]. Thus, this study demonstrated differential effects upon targeting different parts of TGF- $\beta$ pathway and suggests that inhibition of Smad2/3 can inhibit fibrosis while TGF $\beta R 1 / 2$ inhibition can affect fibrosis but also hypertrophy and other aspects of cardiac signaling.

TGF- $\beta 1$ has also been shown to induce cardiomyocyte hypertrophy and post-MI remodeling through the activation of TGF- $\beta$ 1/TAK-p38MAPK signaling within non-infarcted myocardium after acute MI [96]. Thus, inhibition of the TGF- $\beta$ signaling cascade is an attractive target for the prevention of cardiac remodeling and cardiomyopathy post-MI. In this regard, Ellmers et al demonstrated using SD-208 (a TGF- $\beta$ receptor kinase 1 inhibitor) that deleterious cardiac remodeling post-infarction could be inhibited [97]. MI was induced in mice via left coronary artery ligation and were treated with SD-208 for 30 days. While there was no difference recorded in ventricular TGF $\beta$ gene expression, there was increased TAK- 1 (a downstream effector of TGF $\beta$ ) in the control which was inhibited upon treatment with SD-208. The blockade of TGF- $\beta$ signaling after MI resulted in reduced ventricular expression of TGF- $\beta$-activated kinase-1, decreased collagen 1 and decreased cardiac mass highlighting TGF- $\beta$ inhibition as a potent method to reduce cardiac remodeling post-MI [97].

Additionally, as diabetic mortality is primarily due to cardiovascular complications recent studies have sought to investigate whether TGF- $\beta$ inhibition can affect diabetic cardiomyopathy [98]. A study by Zhang et al demonstrated in Sprague-Dawley rats which were induced to become diabetic through the injection of streptozotocin that Matrine (an inhibitor of the TGF- $\beta /$ Smad pathway) administration to rats could prevent diabetic cardiomyopathy as indicated through reduced fibrosis, recovery of LV function and heart compliance [99].

Together these reports demonstrate that inhibition of TGF- $\beta$ signaling via pharmacologic modulation may reduce cardiac fibrosis, improve heart function, and decrease cardiomyopathy in a wide variety of preclinical models. The ultimate goal is to translate these findings to the clinic and improve patient prognosis; however, much work remains to be done to identify effective TGF- $\beta$ inhibitors which can be translated for effective patient therapy. As such, we have identified potential TGF- $\beta$ inhibitors for this purpose which are currently in active and interventional clinical trials for the treatment of cardiotoxicity or heart disease (including heart failure, cardiovascular disease, ischemic heart disease, coronary heart disease and arrhythmia) from the Clinicaltrials.gov database are summarized in Table 1. Identified potential TGF- $\beta$ inhibitors seem to be safe for the usage in clinic and have been demonstrated to suppress the TGF- $\beta$ signaling pathway in preclinical studies; however, further studies will be needed to determine clinical efficacy in combination with chemotherapy as well as the underlying mechanism. 
Table 1: Potential TGF- $\beta$ inhibitors in Active Cardiotoxicity and Cardiac Disease Related Clinical Trials. The Clinicaltrials.gov database was used to assess active, interventional clinical trials for the treatment of heart disease and cardiotoxicity within phase 1 , 2, 3, or 4 of development. Following inhibitor identification, literature was consulted to determine any hypoxia modulating effects. Clinical Trial Search link (accessed on $1 \mathrm{Au}-$ gust 2021): https://clinicaltrials.gov/ct2/results?cond=Cardiotoxicity\&term $=\&$ type $=$ Intr\&rslt=\&recrs $=d \&$ age $~ v=\& g n d r=\& i n t r=\& t i-$ tles $=\&$ outc $=\&$ spons $=\&$ lead $=\& \mathrm{id}=\& \mathrm{cntry}=\&$ state $=\& \mathrm{city}=\&$ dist $=\&$ locn $=\&$ phase $=0$ \&phase $=1$ \&phase $=2 \&$ phase $=3 \& r s u b=\& s t r d ~ s=\& s t r d ~ e=\& p r c d ~ s=\& p r c d \quad e=\& s f p d ~ s=\& s f p d ~ e=\& r f p$ d $\mathrm{s}=\& r f p d \mathrm{e}=\& l u p d \mathrm{~s}=\& l u p d \mathrm{e}=\&$ sort $=$; https://clinicaltrials.gov/ct2/results?cond=Cardiac+Disease\&term $=\&$ type $=I n t r \& r s l t=\&$ recrs $=\mathrm{d} \&$ age $\mathrm{v}=\& g n d r=\& i n t r=\& \mathrm{ti}-$ tles $=$ \&outc $=\&$ spons $=\&$ lead $=\&$ id $=\&$ cntry $=\&$ state $=\&$ city $=\&$ dist $=\&$ locn $=\&$ phase $=0$ \&phase $=1$ \&phase $=2 \&$ phase $=3 \& r s u b=\&$ strd $s=\&$ strd $e=\& p r c d \quad s=\& p r c d \quad e=\& s f p d \quad s=\& s f p d \quad e=\& r f p$ d s=\&rfpd e=\&lupd s=\&lupd e=\&sort=

\begin{tabular}{|c|c|c|c|}
\hline Inhibitor & $\begin{array}{l}\text { Clinical Trial } \\
\text { Number }\end{array}$ & Mechanism & References \\
\hline Enalapril & NCT01968200 & $\begin{array}{l}\text { ACEI with antifibrotic activity via inhibition of TGFB1 and p- } \\
\text { SMAD2/3 expression }\end{array}$ & {$[100,101]$} \\
\hline Carvedilol & $\begin{array}{l}\text { NCT02177175 } \\
\text { NCT01347970 }\end{array}$ & $\begin{array}{l}\text { Suppression of myocardial fibrosis by inhibiting TGFB1 mRNA } \\
\text { expression }\end{array}$ & {$[102,103]$} \\
\hline Simvastatin & NCT02096588 & $\begin{array}{l}\text { Downregulates TGFb1 mediated phosphorylation of Smad 2/3 via } \\
\text { activation of PP2A and PP2C/PPM1A phosphatases. }\end{array}$ & {$[104,105]$} \\
\hline Rivaroxaban & $\begin{array}{l}\text { NCT02303795 } \\
\text { NCT01776424 } \\
\text { NCT02066662 }\end{array}$ & $\begin{array}{l}\text { Downregulates mRNA expression of TGFB in the infarcted area } \\
\text { following an MI potentially via suppression of PAR-1 and PAR-2 } \\
\text { pathways. }\end{array}$ & [106] \\
\hline Clopidogrel & $\begin{array}{l}\text { NCT02044250 } \\
\text { NCT02317198 }\end{array}$ & $\begin{array}{l}\text { Platelet blocker that inhibits the expression of TGFB mRNA and } \\
\text { the protein levels preventing cardiac fibrosis }\end{array}$ & [107] \\
\hline Rituximab & NCT03072199 & $\begin{array}{l}\text { Monoclonal antibody against CD20 inhibits fibrotic signaling of } \\
\text { TGF- } \beta 1 \text { and } p-S m a d 2 / 3\end{array}$ & [108] \\
\hline LCZ696 & NCT02816736 & $\begin{array}{l}\text { Angiotensin receptor-neprilysin inhibitor that improves cardiac } \\
\text { function by downregulates cardiac fibrosis via suppression of }\end{array}$ & {$[109,110]$} \\
\hline
\end{tabular}




\begin{tabular}{|c|c|c|c|}
\hline & $\begin{array}{l}\text { NCT03190304 } \\
\text { NCT02468232 } \\
\text { NCT02924727 }\end{array}$ & $\begin{array}{l}\text { TGF- } \beta \text { expression primarily through its specific inhibition of } \\
\text { neprilysin }\end{array}$ & \\
\hline Spironolactone & $\begin{array}{l}\text { NCT03409627 } \\
\text { NCT02673463 }\end{array}$ & $\begin{array}{l}\text { SP prevents cardiac fibrosis cause by inhibiting the production of } \\
\text { TGF } \beta 1 \text { and phosphorylation of Smad } 2 / 3 \text {. }\end{array}$ & {$[111,112]$} \\
\hline Macitentan & NCT03153111 & $\begin{array}{l}\text { Dual endothelin receptor antagonist (ETA and ETB) that } \\
\text { suppresses expression of TGF } \beta \text {, esp. in DM patients where TGF } \beta \\
\text { is upregulated. }\end{array}$ & {$[113,114]$} \\
\hline Ivabradine & NCT04448899 & $\begin{array}{l}\text { Hyperpolarization-activated pacemaker current (If) channel } \\
\text { inhibitor ivabradine inhibits the expression of TGFb1 and Smad-2 } \\
\text { post MI suppressing collagen synthesis and pro-fibrotic activity. }\end{array}$ & {$[115,116]$} \\
\hline Empagliflozin & $\begin{array}{l}\text { NCT03128528 } \\
\text { NCT03030222 } \\
\text { NCT03057977 } \\
\text { NCT03057951 } \\
\text { NCT03485092 } \\
\text { NCT02998970 }\end{array}$ & $\begin{array}{l}\text { Inhibits the fibrotic activity of TGFb in the heart by suppressing } \\
\text { the expression of TGFb1, p-Smad2/3 and upregulating TGFb } \\
\text { inhibitor Smad7. Further resulting in decreased expression of } \\
\text { collagen I and II mediated by TGFb/Smad pathway. }\end{array}$ & {$[117,118]$} \\
\hline Pirfenidone & NCT02932566 & $\begin{array}{l}\text { Inhibits Ang II induced expression of TGFb1 and suppresses } \\
\text { myocardial interstitial fibrosis. }\end{array}$ & {$[119,120]$} \\
\hline Atorvastatin & NCT02679261 & $\begin{array}{l}\text { Suppresses cardiac fibrosis by attenuating TGFb1 mediated } \\
\text { phosphorylation of Smad3, PI-3 kinase, Akt, collagen I and } \\
\text { endoglin expression. }\end{array}$ & {$[121]$} \\
\hline Eplerenone & NCT01857856 & $\begin{array}{l}\text { Inhibits the expression of TGFb1 and collagen I resulting in } \\
\text { downregulation of cardiac remodeling induced by } \\
\text { cardiomyopathy }\end{array}$ & {$[122]$} \\
\hline Olmesartan & NCT04174456 & $\begin{array}{l}\text { Angiotensin II type } 1 \text { receptor blocker that reduces the expression } \\
\text { of } \mathrm{TGFb} \text { in pressure overloaded, diabetic, obese pts. preventing } \\
\text { cardiovascular injury. }\end{array}$ & {$[123,124]$} \\
\hline
\end{tabular}




\begin{tabular}{|c|c|c|c|}
\hline Tadalafil & NCT03049540 & cGMP mediated inhibition of TGFb1 expression & {$[125]$} \\
\hline Berberine & NCT04434365 & $\begin{array}{l}\text { Antifibrotic activity by inhibition of TGFb1 secretion potentially } \\
\text { by upregulation of AMPK phosphorylation and downregulation } \\
\text { of mTOR and p70S6K phosphorylation. }\end{array}$ & {$[126]$} \\
\hline Melatonin & NCT02099331 & Antifibrotic by suppressing TGFb1expression. & {$[127]$} \\
\hline $\begin{array}{l}\mathrm{N}- \\
\text { Acetylcysteine } \\
\text { (NAC) }\end{array}$ & $\begin{array}{l}\text { NCT02750319 w/ } \\
\text { Amiodarone } \\
\text { NCT01878669 } \\
\text { NCT01878344 }\end{array}$ & $\begin{array}{l}\text { Antioxidant that inhibits TGFb1 mediated signaling involved in } \\
\text { fibrosis potentially by suppressing its interaction with TGB1R, } \\
\text { downregulating phosphorylation of Smad2/3 and upregulating } \\
\text { Smad7 mRNA. }\end{array}$ & {$[128,129$} \\
\hline Colchicine & $\begin{array}{l}\text { NCT02594111 } \\
\text { NCT01709981 } \\
\text { NCT02624180 } \\
\text { NCT04382443 }\end{array}$ & Antifibrotic activity by inhibiting expression of TGFb1 mRNA. & {$[130]$} \\
\hline Ticagrelor & $\begin{array}{l}\text { NCT02539160 } \\
\text { NCT03437044 } \\
\text { NCT01944800 }\end{array}$ & Antifibrotic by inhibiting the expression of TGFb & {$[131]$} \\
\hline Valsartan & NCT01912534 & $\begin{array}{l}\text { Inhibition of Ang II type I (AT 1) receptor resulting in suppression } \\
\text { of AT } 1 \text { mediated action of TGFb/Smad pathway. }\end{array}$ & {$[132]$} \\
\hline Metformin & NCT03629340 & $\begin{array}{l}\text { Suppression of cardiac fibrosis by inhibiting TGFb1 production } \\
\text { and phosphorylation of Smad-3. }\end{array}$ & {$[133]$} \\
\hline Nitrite & $\begin{array}{l}\text { NCT03015402 } \\
\text { NCT02980068 }\end{array}$ & $\begin{array}{l}\text { Downregulation of cardiac remodeling by suppressing AT II and } \\
\text { AT 1R inhibiting TGFb1. }\end{array}$ & {$[134]$} \\
\hline Nebivolol & $\begin{array}{l}\text { NCT02053246 } \\
\text { NCT01648634 }\end{array}$ & $\begin{array}{l}\text { Attenuated profibrotic activity and prevents vascular remodeling } \\
\text { by downregulating the expression of TGFb1and MMP-2/9. }\end{array}$ & {$[135]$} \\
\hline Riociguat & NCT01065454 & $\begin{array}{l}\text { Guyanalate cyclase stimulant with antifibrotic activity by } \\
\text { inhibiting TGFb1 mediated collagen synthesis }\end{array}$ & {$[136]$} \\
\hline
\end{tabular}




\subsection{TGF- $\beta$ as a Therapeutic Target in TNBC}

TGF- $\beta$ signaling has been associated with disease progression and negative patient prognosis in a wide number of cancer models including breast, colon and small cell lung cancers [137-139]. To highlight the clinical importance of TGF- $\beta$ dysregulation; using the cbioportal clinical database in our own analysis we assessed the impact of genomic TGF- $\beta$ alterations (Alterations defined as TGF- $\beta$ genomic mutations, structural variants and copy number variations; see methods for specific genes assessed) in relation with overall patient survival across 32 TCGA, PanCancer Atlas datasets which 10,610 patients [140,141]. $38 \%$ of patients were found to have an alteration in at least one TGF- $\beta$ gene and patients with an alteration in TGF- $\beta$ signaling demonstrated a dramatic reduction in progression free survival compared to patients without TGF- $\beta$ signaling alteration (Figure 1A-B, TGF$\beta$ altered patients: 4047 cases and 47.60 median month progression free survival; TGF- $\beta$ unaltered patients: 6563 cases and 75.48 median month progression free survival). Thus, our findings demonstrate the importance of TGF- $\beta$ in patient outcomes across a broad spectrum of tumor types and datasets (Supplemental Table 1 for detailed list of studies/ cancer studies used for analysis) and in over 10,000 patients. Notably, this analysis does not take into account treatment, age, disease sub-type and other critical factors influencing patient prognosis.

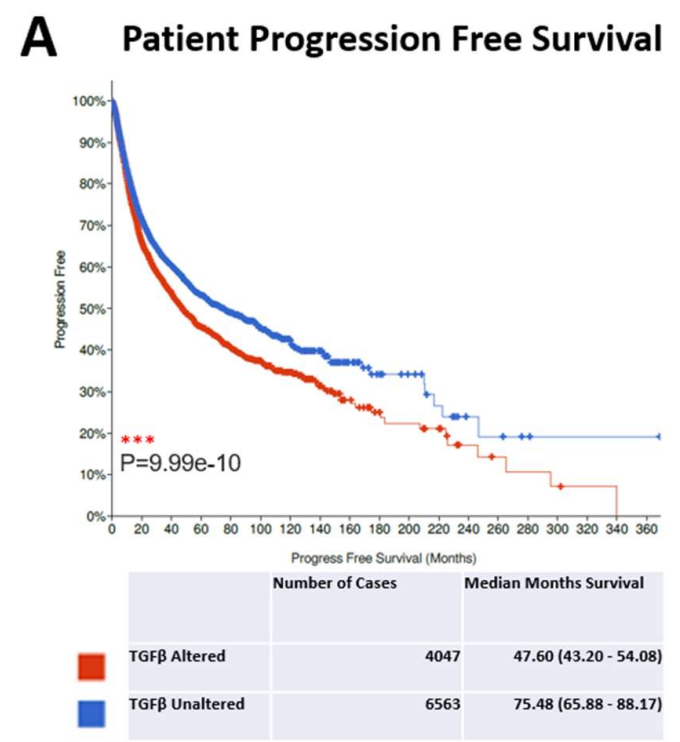

Figure 2: Database Analysis of Patients with TGF- $\beta$ Altered/Unaltered gene expression and Survival. Kaplan-Meier curves for progression free survival of the patients with Alterations in TGF- $\beta$ signaling in cancer samples (red curve) in comparison with patients with unaltered expression (blue curve). $\mathrm{n}=10,610,{ }^{* * *} \mathrm{P}=9.99 \mathrm{e}-10$, log-rank test.

While TGF- $\beta$ alterations are significant in a wide variety of cancer models, it has been found in a study by Ding et al that $52.5 \%$ of TNBC patients were found to have elevated TGF- $\beta$ expression which was associated with increased rates or metastasis, increased tumor grade and negative disease free survival[137]. Moreover, our own previous database analysis revealed similar findings using cbioportal to assess a cohort of 1082 breast cancer patients [142]. It was found that increased TGF- $\beta$ signaling was correlated with diminished overall prognosis and median month survival (122.83 median month survival in patients with TGF- $\beta$ high gene expression versus 140.28 median month survival in 
patients without increased TGF- $\beta$ gene expression)[142]. Moreover, our assessment found that TNBC patients possessed increased levels of TGFBRA mRNA expression and reduced disease-free survival compared to other breast cancer subtypes highlighting the importance of TGF- $\beta$ modulation for prospective treatment [142]. As dysregulated TGF- $\beta$ signaling is associated with increased CSC enrichment, chemoresistance and decreased patient survival in TNBC it highlights TGF- $\beta$ modulation as a potential therapeutic target [143-146].

It has been demonstrated that within breast cancer tumors, the cellular hierarchy is not uniform and a small population (known as cancer stem cells, CSCs) maintains self-renewal and differentiation capabilities regulating tumor composition and heterogeneity. Conversely to differentiated tumor cells, CSCs have demonstrated robust resistance to conventional chemotherapy and are thought to persist following therapy/intervention and are a major cause of relapse [147-149]. A wide number of breast cancer models currently support two distinct sub-populations of CSCs: a mesenchymal CSC population defined by CD $44^{+} / \mathrm{CD} 24^{-}$markers and an epithelial CSC population with $A L D H^{\text {high }}$ markers[150]. Famously Al Hajj et al demonstrated through fractionation experiments of breast tumors that $\mathrm{CD} 44^{+} / \mathrm{CD} 24^{-}$populations were capable of forming a tumor with as little as 100 cells in comparison with the tens of thousands of cells within the different populations required to achieve a similar tumorigenicity[150]. Further characterization experiments demonstrated that $\mathrm{CD}_{4}{ }^{+} / \mathrm{CD} 24-$ mesenchymal CSCs reside at the tumor edge, have diminished E-cadherin and increased vimentin, N-cadherin, YAP signaling and EMT-related migratory pathway enrichment [151-154]. Importantly, this population was found to be associated with increased migration away from the original tumor and markedly increased resistance and quiescence upon exposure to chemotherapy [155]. Conversely,

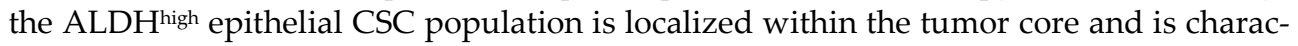
terized by E-cadherin expression, low EMT-related signal enrichment, increased Wnt, HIF1 $\alpha$, glycolytic and proliferative pathway enrichment $[151,154]$. ALDH ${ }^{\text {high }}$ CSCs also demonstrate increased tumorigenicity where as little as 1500 cells are required to form a tumor [156].

It has also been demonstrated that these CSC populations are able to interconvert making therapeutic approaches difficult as simply targeting one population would just lead to reconstitution by the surviving CSCs[154]. Unfortunately, due to the non-specific, toxic nature of conventionally used chemotherapeutic agents such as paclitaxel, doxorubicin, 5-FU or a plethora of other conventional chemotherapeutic agents; administration is associated with resistance and CSC enrichment over time which promotes increased tumorigenicity $[137,157,158]$. Overcoming this obstacle represents a currently unmet medical need and recent findings highlighting TGF- $\beta$ as a mediator of CSC enrichment and resistance is providing valuable insight into how this process may be inhibited. It was found that even short term exposure of TNBC cells to epirubicin (a cytotoxic chemotherapy used for the treatment of TNBC) promoted robust TGF- $\beta$ protein expression which in turn enriched the $\mathrm{CD} 44^{+} / \mathrm{CD} 24-$ mesenchymal CSC population, increased apoptotic resistance and malignancy[159]. Likewise Asiedu et al demonstrated using mouse mammary carcinoma cells (an epithelial tumor cell line) that upon exposure to TGF- $\beta$ /TNF- $\alpha$ promoted a mesenchymal phenotype, increased EMT signature as well as an enrichment of CD44 ${ }^{+} / \mathrm{CD} 24^{-}$ CSCs and mammosphere formation. To determine whether TGF- $\beta$ /TNF- $\alpha$ could transform normal mammary human epithelial cells, MCF10a cells were exposed to TGF- $\beta$ /TNF- $\alpha$ and a similar transformation was observed alongside increased migration and tumorigenicity. These transformed cells were then treated with oxaliplatin, paclitaxel and etoposide and its was found that mammary cells post-TGF- $\beta$ /TNF- $\alpha$ exposure were found to be resistant to chemotherapy[160]. These studies may partially explain the findings of Zhang et al who described that amongst 180 TNBC patients, TGF $\beta 1$ expression was elevated within $37.2 \%$ and associated with a higher histologic tumor grade, lymph node 
status and reduced disease-free survival (hazard ratio $1.796,95 \%$ CI 0.995-3.242, P = 0.052) [161]. Together these studies highlight TGF- $\beta$ signaling as a potent mediator of chemotherapy-induced chemoresistance and tumorigenicity via CSC enrichment. Thus, the development of novel therapies to target TGF- $\beta$ may provide a tangible approach towards patient treatment.

Interestingly, TGF- $\beta$ signaling has been found to regulate the secretion of IL 8 cytokines although the exact mechanism remains convoluted [145,162,163]. Jia et al found using TNBC cell lines in vitro that upon treatment with paclitaxel, doxorubicin or 5-FU, there was robust enrichment in CD44+/CD24- CSCs, mammospheres and cytokine secretion such as IL6 and IL8 through enrichment of NF- $\kappa B$ and STAT3 signaling [164]. These effects were reproduced in a TNBC mouse xenograft model which demonstrated increased tumorigenicity following treatment via serial dilution analysis; however, through NF$\kappa \mathrm{B} / \mathrm{STAT3}$ inhibition in conjunction with chemotherapy, these effects and chemotherapy induced-cytokine mediated CSC enrichment was alleviated [164]. Interestingly, other reports have also demonstrated that paclitaxel induces TGF- $\beta$, IL6 and IL8 transcription in TNBC which in turn promotes increased CSCs and tumorigenicity. Further experiments demonstrated that through siRNA knockdown of SMAD4 or through small molecule inhibition of TGF- $\beta$, chemotherapy induced enrichment of IL8 and subsequent tumorigenicity could be inhibited[145,165]. This association was found to be maintained in breast cancer patients correlating the expression of IL8 and TGF- $\beta$ with diminished patient prognosis making these findings of great clinical importance and highlighting the potential benefit of TGF- $\beta$ inhibitors in combination with conventional chemotherapy[166]. Importantly, when compared to other breast cancer subtypes, TNBC has been found to express increased levels of proinflammatory chemokines (CXCL1,2,3 and 8) compared to the other breast cancer subtypes highlighting the potential sensitivity of TNBC towards antiTGF- $\beta /$ IL6/IL8 targeted therapy [167].

A recent study highlighting the potential clinical application of targeting TGF- $\beta$ regulated cytokine secretion in TNBC demonstrated that comparison amongst TNBC breast cancer biopsies before and after chemotherapy revealed a marked increase in TGF- $\beta$ signaling [145]. Moreover, TGF- $\beta$ expression was associated with increased mammosphere formation and CSC markers (CD44 $/ \mathrm{CD} 24^{-}$and $\mathrm{ALDH}^{\text {high }}$ ) which were associated with increased tumorigenicity[145]. Mechanistic analysis in paclitaxel treated tumors revealed that subsequent TGF- $\beta$ mediated CSC enrichment was through the upregulation and secretion of IL- 8 and its binding to the CXCR1/2 receptors. Moreover, upon addition of a TGF- $\beta R 1$ serine/threonine kinase small molecule inhibitor (LY2157299) in combination with paclitaxel inhibited IL8 expression which correlated with a reduction in both CSC populations following co-therapy. This was highlighted using the gold-standard for tumorigenicity- an in vivo serial dilution assay where compared to the vehicle it was found that Paclitaxel increased the rates of tumor formation while combinational treatment with LY2157299 not only prevent paclitaxel induced tumorigenicity but reduced tumor formation compared to the control. Together this work highlights the therapeutic implications of targeting TGF- $\beta$ signaling in the context of anti-tumorigenic and long-term patient prognosis[145].

Downstream effector inhibition of TGF- $\beta$ signaling has also demonstrated preclinical efficacy. As TGF- $\beta$ has been classically associated in TNBC with metastasis and tumor invasion through facilitation of epithelial to mesenchymal transition (EMT)- a process which can be typically characterized via induction of SNAI1/TWIST1/TWIST2/ZEB1 gene expression[168]. These factors in turn inhibit E-cadherin and its associated signaling; reduce adhesion and promote dissemination[169]. Park et al demonstrated using TNBC tumor xenograft in vivo models that paclitaxel treatment was found to increase TGF- $\beta$ signaling and demonstrated increased SNAI1 gene and protein expression following treatment ( 4 fold 
increase). This correlated with a marked increase in ALDHhigh and CD44+/CD24- CSCs following paclitaxel exposure as well as CSC associated genes (OCT4, NANOG, KLF4, c-MYC and SOX2); however, these effects were reversed upon combinational treatment with the TGF- $\beta / A L K 5$ inhibitor EW-7917. siRNA knockdown of SNAI1 also prevented paclitaxelinduced CSC enrichment supporting that SNAI1 inhibition via TGF- $\beta$ targeting may prevent paclitaxel mediated CSC enrichment in TNBC[170].

More recently, Wardhani et al using a TMEPAI KO TNBC cell model (TMEPAI- Transmembrane prostate androgen-induced protein which involved TGF- $\beta$ signaling via Smaddependent and independent mechanisms and has been found highly expressed in a wide number of cancer models, including breast cancer) found that upon TMEPAI KNO, there was a substantial sensitization towards doxorubicin and paclitaxel treatment reducing the IC50 from approximately $12.5 \mathrm{nM}$ in the control to approximately $4 \mathrm{nM}$ for doxorubicin and from $\sim 30 \mathrm{nM}$ to $\sim 12 \mathrm{nM}$ for paclitaxel treatments[171]. TMEPAI is a TGF- $\beta$ target gene and is highly expressed in TNBC. Moreover, TMEPAI was found to be positively stimulated upon increased TGF- $\beta$ signaling and sensitive to its inhibition[172]. Knockdown of TMEPAI in TNBC led to robust inhibition of in vivo tumor growth accompanied by reduced VEGF and HIF1 $\alpha$ tumor promoters and enhanced levels of PTEN and p27 tumor suppressors [172]. Thus, TMEPAI is thought to affect a wide number of oncogenic pathways in TNBC and be directly mediated through TGF- $\beta$ signaling.

Together these reports highlight the impact of TGF- $\beta$ signaling in conventional chemotherapy resistance generation and CSC enrichment in TNBC. Moreover, these reports highlight TGF- $\beta$ inhibition as a clinically translatable approach to reduce chemotherapeutic-induced CSC enrichment following therapy warranting further investigation. Such a combination may lead to the development of combinational strategies to improve short and long-term efficacy in TNBC patients. In this regard, Active and interventional clinical trials in Clinicaltrials.gov database for the treatment of patients with TNBC are summarized in Table 2 . These potential TGF- $\beta$ inhibitors seem to be safe for the usage in clinic and have been demonstrated to suppress the TGF- $\beta$ signaling pathway in preclinical studies.

Table 1: Potential TGF- $\beta$ inhibitors in Active TNBC Clinical Trials. The Clinicaltrials.gov database was used to assess active, interventional clinical trials for TNBC treatment within phase 1, 2, 3, or 4 of development. Following inhibitor identification, literature was consulted to determine any hypoxia modulating effects. Clinical Trial Search link (accessed on 1 August 2021): https://clinicaltrials.gov/ct2/results?cond=Triple+Negative+Breast+Cancer\&term $=$ \&type $=$ Intr\&rslt=\&recrs=d\&age $\_$v $=$\&gndr=Female\&intr $=\& t i-$

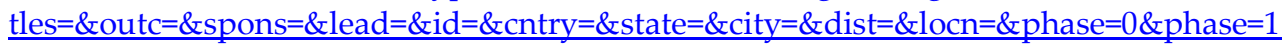
\&phase $=2$ \&phase $=3 \&$ rsub=\&strd $\mathrm{s}=$ \&strd $\mathrm{e}=$ \&prcd $\mathrm{s}=$ \&prcd $\mathrm{e}=$ \&sfpd $\mathrm{s}=\&$ sfpd $\mathrm{e}=$ \&rfp d $\mathrm{s}=\&$ \&fpd e=\&lupd $\mathrm{s}=\&$ lupd $\mathrm{e}=$ \&sort $=$

\begin{tabular}{|c|c|c|c|}
\hline Inhibitor & $\begin{array}{c}\text { Clinical Trial } \\
\text { Number }\end{array}$ & Mechanism & References \\
\hline Sorafenib & $\begin{array}{c}\text { NCT02624700 - w/ } \\
\text { Pemetrexed }\end{array}$ & $\begin{array}{c}\text {-Suppression of TGFb1 mediated EMT via epigenetic } \\
\text { modification of TGFb1 and Smad2/3 promoters through loss } \\
\text { of active histone markers (H3K4me3 and/or H3K9ac). } \\
\text { - Has also been shown to disrupt the phosphorylation of } \\
\text { Smad2/3 }\end{array}$ & {$[173,174]$} \\
\hline
\end{tabular}




\begin{tabular}{|c|c|c|c|}
\hline & & -Suppression of TGFb signaling in hepatocellular carcinoma & \\
\hline $\begin{array}{l}\text { Halaven } \\
\text { (eribulin } \\
\text { mesylate) }\end{array}$ & $\begin{array}{l}\text { NCT01372579 - w/ } \\
\text { Carboplatin } \\
\text { NCT02120469 }\end{array}$ & $\begin{array}{l}\text { Suppresses metastasis by inhibiting TGFb mediated } \\
\text { phosphorylation of Smad } 2 / 3 \\
\text { (Potentially by altering the interactions between Smad } \\
\text { proteins and microtubules following erlubin binding) }\end{array}$ & {$[175,176]$} \\
\hline $\begin{array}{c}\text { Pembrolizumab } \\
\text { (MK-3475) }\end{array}$ & $\begin{array}{c}\text { NCT02644369 } \\
\text { NCT02730130 } \\
\text { NCT02734290 } \\
\text { NCT03036488 } \\
\text { NCT02555657 } \\
\text { NCT02819518 } \\
\text { NCT02981303 - w/ } \\
\text { Imprime PGG } \\
\text { NCT03567720 } \\
\text { NCT02657889 - w/ } \\
\text { Niraparib } \\
\text { NCT02971761- w/ } \\
\text { Enobosarm } \\
\text { NCT01676753 - w/ } \\
\text { Dinaciclib } \\
\text { NCT02178722 }\end{array}$ & $\begin{array}{l}\text { Decreased the production of TGFb in tumor } \\
\text { microenvironment }\end{array}$ & {$[177,178]$} \\
\hline Apatinib & $\begin{array}{l}\text { NCT03075462 } \\
\text { NCT03394287 }\end{array}$ & Downregulates TGFb1 pathway & [179] \\
\hline
\end{tabular}

\subsection{Conclusion and Future Directions}

Heart disease is a leading cause of mortality amongst breast cancer patients due to the reliance on cardiotoxic, non-specific chemotherapies for treatment [6]. While chemotherapy is an essential part of therapy, the development of novel methods to modulate its cardiotoxic effects are critical. TGF- $\beta$ has been demonstrated to be upregulated postchemotherapeutic exposure in patients which is in turn associated with increased fibrosis, cardiac hypertrophy and inflammation impacting both short and long-term patient prognosis [86-89,180]. Moreover, it has been found that through inhibition of TGF- $\beta$ these adverse effects can be limited, thus TGF- $\beta$ inhibitors combined with chemotherapy may be a tangible approach to increase patient prognosis and reduce cardiovascular disease.

Additionally, TGF- $\beta$ has been associated with post-chemotherapeutic enrichment of $\mathrm{CD}_{4}+\mathrm{CD} 24-$ mesenchymal and ALDH ${ }^{\text {high }}$ epithelial CSCs which are a major barrier against successful long-term patient survival through promotion of tumorigenicity, metastasis and resistance. TGF- $\beta$ inhibition in preclinical models have demonstrated promising results in regards to inhibition of both CSC populations and prevention of chemotherapy induced CSC enrichment following combinational treatment. This is important as treatment of CSCs are essential for effective treatment of TNBC and prevention of chemotherapy-induced CSCs may reduce the rate of metastasis, relapse and increase patient 
prognosis. Therefore, the investigation into TGF- $\beta$ inhibition as a treatment for TNBC CSCs remains of great importance and of great clinical translational value.

Together TGF- $\beta$ inhibition represents an intersection in two fields: cardiology and oncology. On one side, cardiomyopathy, cardiac fibrosis, cardiac damage and heart failure may be prevented and on the other side, tumor efficacy may be enhanced and chemotherapeutically induced CSCs may be inhibited. Together both of these approaches, if successfully implemented would target the two greatest causes of cancer-related morbidity in patients and potentially lead to a breakthrough therapy.

\subsection{Materials and Methods}

\section{Clinical Database Analysis}

Pan-cancer datasets from the Cancer Genome Atlas PanCancer Atlas (TCGA, https://www.cell.com/pb-assets/consortium/pancanceratlas/pancani3/index.html) were used and analyzed with cBioportal (http://www.cbioportal.org/index.do). Altered TGF- $\beta$ were defined as mutations, structural variants and/or copy number alterations in one of the following genes composing the TGFB superfamily: TGFB1 TGFB2 TGFB3 TGFBR1 TGFBR2 TGFBR3 BMP2 BMP3 BMP4 BMP5 BMP6 BMP7 GDF2 BMP10 BMP15 BMPR1A BMPR1B BMPR2 ACVR1 ACVR1B ACVR1C ACVR2A ACVR2B ACVRL1 NODAL GDF1 GDF11 INHA INHBA INHBB INHBC INHBE SMAD2 SMAD3 SMAD1 SMAD5 SMAD4 SMAD9 SMAD6 SMAD7 SPTBN1 TGFBRAP1 and/or ZFYVE9. Kaplan-Meier survival curves were generated using the datasets compiled by January 2022 from the following database IDs: https://bit.ly/2BngXkv

Supplementary Materials: The following are available online at www.mdpi.com/xxx/s1, Figure S1: List Cancer Types Across 32 Studies Used for Database Analysis

Author Contributions: Conceptualization, A.S. and S.M.; Methodology, A.S.; Writing-original draft preparation, A.S, J.C, S.M, R.K, S.C, V.V.; writing - review and editing, A.S, S.M, R.K, J.C, S.C, V.V.; visualization, A.S and S.M.; supervision, A.S. All authors have read and agreed to the published version of the manuscript.

Funding: This research did not receive any specific grant from funding agencies in the public, commercial, or not-for-profit sectors.

Acknowledgments: I would like to thank Dr. Eugene Konorev for his help in developing the concept of TGF- $\beta$ being a key modulator of cardiac morbidity and as a potential method to increase TNBC tumor efficacy. I would like to thank Brandon Sulaiman for his help with revising the manuscript. We thank Dr. Luk Cox and Dr. Idoya Lahortiga from Somersault 18:24 to allow the use of their Library of Science and Medical Illustrations (http://www.somersault1824.com/resources/) for the creation of Figure 1 and the Graphical Abstract.

Conflicts of Interest: The authors declare no conflict of interest

\section{References}

1. Bray, F.; Ferlay, J.; Soerjomataram, I.; Siegel, R.L.; Torre, L.A.; Jemal, A.J.C.a.c.j.f.c. Global cancer statistics 2018: GLOBOCAN estimates of incidence and mortality worldwide for 36 cancers in 185 countries. 2018, 68, 394-424.

2. Anders, C.K.; Carey, L.A.J.C.b.c. Biology, metastatic patterns, and treatment of patients with triple-negative breast cancer. 2009, 9, S73S81. 
3. Bauer, K.R.; Brown, M.; Cress, R.D.; Parise, C.A.; Caggiano, V.J.C. Descriptive analysis of estrogen receptor (ER)-negative, progesterone receptor (PR)-negative, and HER2-negative invasive breast cancer, the so-called triple-negative phenotype: a population-based study from the California cancer Registry. 2007, 109, 1721-1728.

4. Chen, J.; Long, J.B.; Hurria, A.; Owusu, C.; Steingart, R.M.; Gross, C.P.J.J.o.t.A.C.o.C. Incidence of heart failure or cardiomyopathy after adjuvant trastuzumab therapy for breast cancer. 2012, 60, 2504-2512.

5. Tan, C.; Denlinger, C.J.A.C.C.E.A. Cardiovascular toxicity in cancer survivors: current guidelines and future directions. $2018,29$.

6. Patnaik, J.L.; Byers, T.; DiGuiseppi, C.; Dabelea, D.; Denberg, T.D.J.B.C.R. Cardiovascular disease competes with breast cancer as the leading cause of death for older females diagnosed with breast cancer: a retrospective cohort study. 2011, 13, R64.

7. Bardia, A.; Arieas, E.T.; Zhang, Z.; DeFilippis, A.; Tarpinian, K.; Jeter, S.; Nguyen, A.; Henry, N.L.; Flockhart, D.A.; Hayes, D.F.J.B.c.r.; et al. Comparison of breast cancer recurrence risk and cardiovascular disease incidence risk among postmenopausal women with breast cancer. 2012, 131, 907-914.

8. Sturgeon, K.M.; Deng, L.; Bluethmann, S.M.; Zhou, S.; Trifiletti, D.M.; Jiang, C.; Kelly, S.P.; Zaorsky, N.G.J.E.h.j. A population-based study of cardiovascular disease mortality risk in US cancer patients. 2019, 40, 3889-3897.

9. Clarke, M.; Coates, A.S.; Darby, S.C.; Davies, C.; Gelber, R.D.; Godwin, J.; Goldhirsch, A.; Gray, R.; Peto, R.; Pritchard, K.I.; et al. Adjuvant chemotherapy in oestrogen-receptor-poor breast cancer: patient-level meta-analysis of randomised trials. Lancet 2008, 371, 29-40, doi:10.1016/S0140-6736(08)60069-0.

10. Ozkan, M.; Berk, V.; Kaplan, M.A.; Benekli, M.; Coskun, U.; Bilici, A.; Gumus, M.; Alkis, N.; Dane, F.; Ozdemir, N.Y.; et al. Gemcitabine and cisplatin combination chemotherapy in triple negative metastatic breast cancer previously treated with a taxane/anthracycline chemotherapy; multicenter experience. Neoplasma 2012,59, 38-42, doi:10.4149/neo_2012_005.

11. Singal, P.K.; lliskovic, N. Doxorubicin-induced cardiomyopathy. N Eng/J Med 1998, 339, 900-905, doi:10.1056/NEJM199809243391307.

12. Mercuro, G.; Cadeddu, C.; Piras, A.; Dessì, M.; Madeddu, C.; Deidda, M.; Serpe, R.; Massa, E.; Mantovani, G. Early epirubicin-induced myocardial dysfunction revealed by serial tissue Doppler echocardiography: correlation with inflammatory and oxidative stress markers. Oncologist 2007, 12, 1124-1133, doi:10.1634/theoncologist.12-9-1124.

13. Albini, A.; Pennesi, G.; Donatelli, F.; Cammarota, R.; De Flora, S.; Noonan, D.M. Cardiotoxicity of anticancer drugs: the need for cardiooncology and cardio-oncological prevention. J Natl Cancer Inst 2010, 102, 14-25, doi:10.1093/jnci/djp440.

14. Pai, V.B.; Nahata, M.C. Cardiotoxicity of chemotherapeutic agents: incidence, treatment and prevention. Drug Saf 2000, 22, 263-302, doi:10.2165/00002018-200022040-00002.

15. Ewer, M.S.; Lippman, S.M. Type II chemotherapy-related cardiac dysfunction: time to recognize a new entity. J Clin Oncol 2005, 23, 2900-2902, doi:10.1200/JCO.2005.05.827.

16. Davies, K.J.; Doroshow, J.H. Redox cycling of anthracyclines by cardiac mitochondria. I. Anthracycline radical formation by NADH dehydrogenase. J Biol Chem 1986, 261, 3060-3067.

17. Berthiaume, J.M.; Wallace, K.B. Adriamycin-induced oxidative mitochondrial cardiotoxicity. Cell Biol Toxicol 2007, 23, 15-25, doi:10.1007/s10565-006-0140-y.

18. Barth, E.; Stämmler, G.; Speiser, B.; Schaper, J. Ultrastructural quantitation of mitochondria and myofilaments in cardiac muscle from 10 different animal species including man. J Mol Cell Cardiol 1992, 24, 669-681, doi:10.1016/0022-2828(92)93381-s.

19. Simůnek, T.; Stérba, M.; Popelová, O.; Adamcová, M.; Hrdina, R.; Gersl, V. Anthracycline-induced cardiotoxicity: overview of studies examining the roles of oxidative stress and free cellular iron. Pharmacol Rep 2009, 61, 154-171, doi:10.1016/s1734-1140(09)70018-0.

20. Thomas, C.E.; Aust, S.D. Release of iron from ferritin by cardiotoxic anthracycline antibiotics. Arch Biochem Biophys 1986, 248, 684689, doi:10.1016/0003-9861(86)90523-0.

21. Wang, S.; Leonard, S.S.; Ye, J.; Ding, M.; Shi, X. The role of hydroxyl radical as a messenger in Cr(VI)-induced p53 activation. Am J Physiol Cell Physiol 2000, 279, C868-875, doi:10.1152/ajpcell.2000.279.3.C868.

22. Wang, J.C. Cellular roles of DNA topoisomerases: a molecular perspective. Nat Rev Mol Cell Bio/ 2002, 3, 430-440, doi:10.1038/nrm831. 
23. Capranico, G.; Tinelli, S.; Austin, C.A.; Fisher, M.L.; Zunino, F. Different patterns of gene expression of topoisomerase II isoforms in differentiated tissues during murine development. Biochim Biophys Acta 1992, 1132, 43-48, doi:10.1016/0167-4781(92)90050-a.

24. Zhang, S.; Liu, X.; Bawa-Khalfe, T.; Lu, L.S.; Lyu, Y.L.; Liu, L.F.; Yeh, E.T. Identification of the molecular basis of doxorubicin-induced cardiotoxicity. Nat Med 2012, 18, 1639-1642, doi:10.1038/nm.2919.

25. Gehl, J.; Boesgaard, M.; Paaske, T.; Vittrup Jensen, B.; Dombernowsky, P. Combined doxorubicin and paclitaxel in advanced breast cancer: effective and cardiotoxic. Ann Oncol 1996, 7, 687-693, doi:10.1093/oxfordjournals.annonc.a010717.

26. Chan, S.; Friedrichs, K.; Noel, D.; Pintér, T.; Van Belle, S.; Vorobiof, D.; Duarte, R.; Gil Gil, M.; Bodrogi, I.; Murray, E.; et al. Prospective randomized trial of docetaxel versus doxorubicin in patients with metastatic breast cancer. J Clin Oncol 1999, 17, 2341-2354, doi:10.1200/JCO.1999.17.8.2341.

27. Rowinsky, E.K.; McGuire, W.P.; Guarnieri, T.; Fisherman, J.S.; Christian, M.C.; Donehower, R.C. Cardiac disturbances during the administration of taxol. J Clin Oncol 1991, 9, 1704-1712, doi:10.1200/JCO.1991.9.9.1704.

28. McGuire, W.P.; Rowinsky, E.K.; Rosenshein, N.B.; Grumbine, F.C.; Ettinger, D.S.; Armstrong, D.K.; Donehower, R.C. Taxol: a unique antineoplastic agent with significant activity in advanced ovarian epithelial neoplasms. Ann Intern Med 1989, 111, 273-279, doi:10.7326/0003-4819-111-4-273.

29. Bristow, M.R.; Sageman, W.S.; Scott, R.H.; Billingham, M.E.; Bowden, R.E.; Kernoff, R.S.; Snidow, G.H.; Daniels, J.R. Acute and chronic cardiovascular effects of doxorubicin in the dog: the cardiovascular pharmacology of drug-induced histamine release. J Cardiovasc Pharmacol 1980, 2, 487-515, doi:10.1097/00005344-198009000-00002.

30. Gianni, L.; Munzone, E.; Capri, G.; Fulfaro, F.; Tarenzi, E.; Villani, F.; Spreafico, C.; Laffranchi, A.; Caraceni, A.; Martini, C. Paclitaxel by 3hour infusion in combination with bolus doxorubicin in women with untreated metastatic breast cancer: high antitumor efficacy and cardiac effects in a dose-finding and sequence-finding study. J Clin Oncol 1995, 13, 2688-2699, doi:10.1200/JCO.1995.13.11.2688.

31. Gianni, L.; Viganò, L.; Locatelli, A.; Capri, G.; Giani, A.; Tarenzi, E.; Bonadonna, G. Human pharmacokinetic characterization and in vitro study of the interaction between doxorubicin and paclitaxel in patients with breast cancer. J Clin Oncol 1997, 15, 1906-1915, doi:10.1200/JCO.1997.15.5.1906.

32. Piver, M.S.; Marchetti, D.L.; Parthasarathy, K.L.; Bakshi, S.; Reese, P. Doxorubicin hydrochloride (Adriamycin) cardiotoxicity evaluated by sequential radionuclide angiocardiography. Cancer 1985, 56, 76-80, doi:10.1002/1097-0142(19850701)56:1<76::aidcncr2820560113>3.0.co;2-s.

33. van Royen, N.; Jaffe, C.C.; Krumholz, H.M.; Johnson, K.M.; Lynch, P.J.; Natale, D.; Atkinson, P.; Deman, P.; Wackers, F.J. Comparison and reproducibility of visual echocardiographic and quantitative radionuclide left ventricular ejection fractions. Am J Cardiol 1996, 77, 843-850, doi:10.1016/s0002-9149(97)89179-5.

34. Seidman, A.; Hudis, C.; Pierri, M.K.; Shak, S.; Paton, V.; Ashby, M.; Murphy, M.; Stewart, S.J.; Keefe, D. Cardiac dysfunction in the trastuzumab clinical trials experience. J Clin Oncol 2002, 20, 1215-1221, doi:10.1200/JCO.2002.20.5.1215.

35. Martín, M.; Esteva, F.J.; Alba, E.; Khandheria, B.; Pérez-Isla, L.; García-Sáenz, J.A.; Márquez, A.; Sengupta, P.; Zamorano, J. Minimizing cardiotoxicity while optimizing treatment efficacy with trastuzumab: review and expert recommendations. Oncologist 2009, 14, 1-11, doi:10.1634/theoncologist.2008-0137.

36. Swain, S.M.; Whaley, F.S.; Ewer, M.S. Congestive heart failure in patients treated with doxorubicin: a retrospective analysis of three trials. Cancer 2003, 97, 2869-2879, doi:10.1002/cncr.11407.

37. Hoffmann, R.; von Bardeleben, S.; ten Cate, F.; Borges, A.C.; Kasprzak, J.; Firschke, C.; Lafitte, S.; Al-Saadi, N.; Kuntz-Hehner, S.; Engelhardt, M.; et al. Assessment of systolic left ventricular function: a multi-centre comparison of cineventriculography, cardiac magnetic resonance imaging, unenhanced and contrast-enhanced echocardiography. Eur Heart J 2005, 26, 607-616, doi:10.1093/eurheartj/ehi083.

38. Jiji, R.S.; Kramer, C.M.; Salerno, M. Non-invasive imaging and monitoring cardiotoxicity of cancer therapeutic drugs. J Nucl Cardio/ 2012, 19, 377-388, doi:10.1007/s12350-012-9512-2. 
39. Mitani, I.; Jain, D.; Joska, T.M.; Burtness, B.; Zaret, B.L. Doxorubicin cardiotoxicity: prevention of congestive heart failure with serial cardiac function monitoring with equilibrium radionuclide angiocardiography in the current era. J Nucl Cardiol 2003, 10, 132-139, doi:10.1067/mnc.2003.7.

40. Hendel, R.C.; Patel, M.R.; Kramer, C.M.; Poon, M.; Carr, J.C.; Gerstad, N.A.; Gillam, L.D.; Hodgson, J.M.; Kim, R.J.; Lesser, J.R.; et al. ACCF/ACR/SCCT/SCMR/ASNC/NASCI/SCAI/SIR 2006 appropriateness criteria for cardiac computed tomography and cardiac magnetic resonance imaging: a report of the American College of Cardiology Foundation Quality Strategic Directions Committee Appropriateness Criteria Working Group, American College of Radiology, Society of Cardiovascular Computed Tomography, Society for Cardiovascular Magnetic Resonance, American Society of Nuclear Cardiology, North American Society for Cardiac Imaging, Society for Cardiovascular Angiography and Interventions, and Society of Interventional Radiology. J Am Coll Cardiol 2006, 48, 1475-1497, doi:10.1016/j.jacc.2006.07.003.

41. Horacek, J.M.; Jakl, M.; Horackova, J.; Pudil, R.; Jebavy, L.; Maly, J. Assessment of anthracycline-induced cardiotoxicity with electrocardiography. Exp Oncol 2009, 31, 115-117.

42. Fukumi, D.; Uchikoba, Y.; Maeda, M.; Ogawa, S. Longitudinal evaluation of anthracycline cardiotoxicity by signal-averaged electrocardiography in children with cancer. Pediatr Int 2002, 44, 134-140, doi:10.1046/j.1328-8067.2001.01526.x.

43. Adamcová, M.; Šimůnek, T.; Kaiserová, H.; Popelová, O.; Štěrba, M.; Potáčová, A.; Vávrová, J.; Maláková, J.; Geršl, V. In vitro and in vivo examination of cardiac troponins as biochemical markers of drug-induced cardiotoxicity. Toxicology 2007, 237, 218-228, doi:10.1016/j.tox.2007.05.016.

44. Cardinale, D.; Sandri, M.T.; Colombo, A.; Colombo, N.; Boeri, M.; Lamantia, G.; Civelli, M.; Peccatori, F.; Martinelli, G.; Fiorentini, C.; et al. Prognostic value of troponin I in cardiac risk stratification of cancer patients undergoing high-dose chemotherapy. Circulation 2004, 109, 2749-2754, doi:10.1161/01.CIR.0000130926.51766.CC.

45. Cardinale, D.; Sandri, M.T.; Martinoni, A.; Tricca, A.; Civelli, M.; Lamantia, G.; Cinieri, S.; Martinelli, G.; Cipolla, C.M.; Fiorentini, C. Left ventricular dysfunction predicted by early troponin I release after high-dose chemotherapy. J Am Coll Cardiol 2000, 36, 517-522, doi:10.1016/s0735-1097(00)00748-8.

46. Cao, L.; Zhu, W.; Wagar, E.A.; Meng, Q.H. Biomarkers for monitoring chemotherapy-induced cardiotoxicity. Crit Rev Clin Lab Sci 2017, 54, 87-101, doi:10.1080/10408363.2016.1261270.

47. Suga, S.; Nakao, K.; Hosoda, K.; Mukoyama, M.; Ogawa, Y.; Shirakami, G.; Arai, H.; Saito, Y.; Kambayashi, Y.; Inouye, K. Receptor selectivity of natriuretic peptide family, atrial natriuretic peptide, brain natriuretic peptide, and C-type natriuretic peptide. Endocrinology 1992, 130, 229-239, doi:10.1210/endo.130.1.1309330.

48. Babuin, L.; Jaffe, A.S. Troponin: the biomarker of choice for the detection of cardiac injury. CMAJ 2005, 173, 1191-1202, doi:10.1503/cmaj/051291.

49. Romano, S.; Fratini, S.; Ricevuto, E.; Procaccini, V.; Stifano, G.; Mancini, M.; Di Mauro, M.; Ficorella, C.; Penco, M. Serial measurements of NT-proBNP are predictive of not-high-dose anthracycline cardiotoxicity in breast cancer patients. Br J Cancer 2011, 105, 1663-1668, doi:10.1038/bjc.2011.439.

50. Katus, H.A.; Remppis, A.; Looser, S.; Hallermeier, K.; Scheffold, T.; Kübler, W. Enzyme linked immuno assay of cardiac troponin T for the detection of acute myocardial infarction in patients. J Mol Cell Cardiol 1989, 21, 1349-1353, doi:10.1016/0022-2828(89)90680-9.

51. Lenihan, D.J.; Stevens, P.L.; Massey, M.; Plana, J.C.; Araujo, D.M.; Fanale, M.A.; Fayad, L.E.; Fisch, M.J.; Yeh, E.T. The Utility of Point-ofCare Biomarkers to Detect Cardiotoxicity During Anthracycline Chemotherapy: A Feasibility Study. J Card Fail 2016, 22, 433-438, doi:10.1016/j.cardfail.2016.04.003.

52. Feola, M.; Garrone, O.; Occelli, M.; Francini, A.; Biggi, A.; Visconti, G.; Albrile, F.; Bobbio, M.; Merlano, M. Cardiotoxicity after anthracycline chemotherapy in breast carcinoma: effects on left ventricular ejection fraction, troponin I and brain natriuretic peptide. Int J Cardiol 2011, 148, 194-198, doi:10.1016/j.ijcard.2009.09.564. 
53. Toba, H.; Lindsey, M.L. Extracellular matrix roles in cardiorenal fibrosis: Potential therapeutic targets for CVD and CKD in the elderly. Pharmacol Ther 2019, 193, 99-120, doi:10.1016/j.pharmthera.2018.08.014.

54. Biernacka, A.; Dobaczewski, M.; Frangogiannis, N.G. TGF- $\beta$ signaling in fibrosis. Growth Factors 2011, 29, 196-202, doi:10.3109/08977194.2011.595714.

55. Sarrazy, V.; Koehler, A.; Chow, M.L.; Zimina, E.; Li, C.X.; Kato, H.; Caldarone, C.A.; Hinz, B. Integrins $\alpha v \beta 5$ and $\alpha v \beta 3$ promote latent TGF$\beta 1$ activation by human cardiac fibroblast contraction. Cardiovasc Res 2014, 102, 407-417, doi:10.1093/cvr/cvu053.

56. Shi, M.; Zhu, J.; Wang, R.; Chen, X.; Mi, L.; Walz, T.; Springer, T.A. Latent TGF- $\beta$ structure and activation. Nature 2011, 474, 343-349, doi:10.1038/nature10152.

57. Zhou, Y.; Hagood, J.S.; Lu, B.; Merryman, W.D.; Murphy-Ullrich, J.E. Thy-1-integrin alphav beta5 interactions inhibit lung fibroblast contraction-induced latent transforming growth factor-beta1 activation and myofibroblast differentiation. J Biol Chem 2010, 285, 22382-22393, doi:10.1074/jbc.M110.126227.

58. Bujak, M.; Frangogiannis, N.G. The role of TGF-beta signaling in myocardial infarction and cardiac remodeling. Cardiovasc Res 2007, 74, 184-195, doi:10.1016/j.cardiores.2006.10.002.

59. Walton, K.L.; Johnson, K.E.; Harrison, C.A. Targeting TGF- $\beta$ Mediated SMAD Signaling for the Prevention of Fibrosis. Front Pharmacol 2017, 8, 461, doi:10.3389/fphar.2017.00461.

60. Flevaris, P.; Vaughan, D. The Role of Plasminogen Activator Inhibitor Type-1 in Fibrosis. Semin Thromb Hemost 2017, 43, 169-177, doi:10.1055/s-0036-1586228.

61. Lipson, K.E.; Wong, C.; Teng, Y.; Spong, S. CTGF is a central mediator of tissue remodeling and fibrosis and its inhibition can reverse the process of fibrosis. Fibrogenesis Tissue Repair 2012, 5, S24, doi:10.1186/1755-1536-5-s1-s24.

62. Finnson, K.W.; Almadani, Y.; Philip, A. Non-canonical (non-SMAD2/3) TGF- $\beta$ signaling in fibrosis: Mechanisms and targets. Semin Cell Dev Biol 2020, 101, 115-122, doi:10.1016/j.semcdb.2019.11.013.

63. Zhang, Y.E. Non-Smad Signaling Pathways of the TGF- $\beta$ Family. Cold Spring Harb Perspect Biol 2017, 9, doi:10.1101/cshperspect.a022129.

64. Działo, E.; Tkacz, K.; Błyszczuk, P. Crosstalk between the TGF- $\beta$ and WNT signalling pathways during cardiac fibrogenesis. Acta Biochim Pol 2018, 65, 341-349, doi:10.18388/abp.2018_2635.

65. Bansal, T.; Chatterjee, E.; Singh, J.; Ray, A.; Kundu, B.; Thankamani, V.; Sengupta, S.; Sarkar, S. Arjunolic acid, a peroxisome proliferatoractivated receptor $\alpha$ agonist, regresses cardiac fibrosis by inhibiting non-canonical TGF- $\beta$ signaling. J Biol Chem 2017, 292, 1644016462, doi:10.1074/jbc.M117.788299.

66. Zhang, Y.E. Non-Smad pathways in TGF-beta signaling. Cell Res 2009, 19, 128-139, doi:10.1038/cr.2008.328.

67. Burchfield, J.S.; Xie, M.; Hill, J.A. Pathological ventricular remodeling: mechanisms: part 1 of 2. Circulation 2013, 128, 388-400, doi:10.1161/CIRCULATIONAHA.113.001878.

68. Hanna, A.; Frangogiannis, N.G. The Role of the TGF-beta Superfamily in Myocardial Infarction. Front Cardiovasc Med 2019, 6, 140, doi:10.3389/fcvm.2019.00140.

69. Holweg, C.T.; Baan, C.C.; Niesters, H.G.; Vantrimpont, P.J.; Mulder, P.G.; Maat, A.P.; Weimar, W.; Balk, A.H. TGF-beta1 gene polymorphisms in patients with end-stage heart failure. J Heart Lung Transplant 2001, 20, 979-984, doi:10.1016/s1053-2498(01)002960 .

70. Cho, N.; Razipour, S.E.; McCain, M.L. Featured Article: TGF-beta1 dominates extracellular matrix rigidity for inducing differentiation of human cardiac fibroblasts to myofibroblasts. Exp Biol Med (Maywood) 2018, 243, 601-612, doi:10.1177/1535370218761628.

71. Liguori, T.T.A.; Liguori, G.R.; Moreira, L.F.P.; Harmsen, M.C. Fibroblast growth factor-2, but not the adipose tissue-derived stromal cells secretome, inhibits TGF- $\beta 1$-induced differentiation of human cardiac fibroblasts into myofibroblasts. Sci Rep 2018, 8, 16633, doi:10.1038/s41598-018-34747-3. 
72. Desmouliere, A.; Geinoz, A.; Gabbiani, F.; Gabbiani, G. Transforming growth factor-beta 1 induces alpha-smooth muscle actin expression in granulation tissue myofibroblasts and in quiescent and growing cultured fibroblasts. J Cell Biol 1993, 122, 103-111, doi:10.1083/jcb.122.1.103.

73. Dobaczewski, M.; Bujak, M.; Li, N.; Gonzalez-Quesada, C.; Mendoza, L.H.; Wang, X.F.; Frangogiannis, N.G. Smad3 signaling critically regulates fibroblast phenotype and function in healing myocardial infarction. Circ Res 2010, 107, 418-428, doi:10.1161/CIRCRESAHA.109.216101.

74. Gerarduzzi, C.; Di Battista, J.A. Myofibroblast repair mechanisms post-inflammatory response: a fibrotic perspective. Inflamm Res 2017, 66, 451-465, doi:10.1007/s00011-016-1019-x.

75. Kong, P.; Christia, P.; Frangogiannis, N.G. The pathogenesis of cardiac fibrosis. Cell Mol Life Sci 2014, 71, 549-574, doi:10.1007/s00018013-1349-6.

76. Bujak, M.; Ren, G.; Kweon, H.J.; Dobaczewski, M.; Reddy, A.; Taffet, G.; Wang, X.F.; Frangogiannis, N.G. Essential role of Smad3 in infarct healing and in the pathogenesis of cardiac remodeling. Circulation 2007, 116, 2127-2138, doi:10.1161/CIRCULATIONAHA.107.704197.

77. Khalil, H.; Kanisicak, O.; Prasad, V.; Correll, R.N.; Fu, X.; Schips, T.; Vagnozzi, R.J.; Liu, R.; Huynh, T.; Lee, S.J.; et al. Fibroblast-specific TGF-beta-Smad2/3 signaling underlies cardiac fibrosis. J Clin Invest 2017, 127, 3770-3783, doi:10.1172/JCI94753.

78. Gao, X.; He, X.; Luo, B.; Peng, L.; Lin, J.; Zuo, Z. Angiotensin II increases collagen I expression via transforming growth factor-beta1 and extracellular signal-regulated kinase in cardiac fibroblasts. Eur J Pharmacol 2009, 606, 115-120, doi:10.1016/j.ejphar.2008.12.049.

79. Rosenkranz, S. TGF-beta1 and angiotensin networking in cardiac remodeling. Cardiovasc Res 2004, 63, 423-432, doi:10.1016/j.cardiores.2004.04.030.

80. Wong, C.K.S.; Falkenham, A.; Myers, T.; Légaré, J.F. Connective tissue growth factor expression after angiotensin II exposure is dependent on transforming growth factor- $\beta$ signaling via the canonical Smad-dependent pathway in hypertensive induced myocardial fibrosis. J Renin Angiotensin Aldosterone Syst 2018, 19, 1470320318759358, doi:10.1177/1470320318759358.

81. Wang, W.; Huang, X.R.; Canlas, E.; Oka, K.; Truong, L.D.; Deng, C.; Bhowmick, N.A.; Ju, W.; Bottinger, E.P.; Lan, H.Y. Essential role of Smad3 in angiotensin II-induced vascular fibrosis. Circ Res 2006, 98, 1032-1039, doi:10.1161/01.RES.0000218782.52610.dc.

82. Zhang, R.; Zhang, Y.Y.; Huang, X.R.; Wu, Y.; Chung, A.C.; Wu, E.X.; Szalai, A.J.; Wong, B.C.; Lau, C.P.; Lan, H.Y. C-reactive protein promotes cardiac fibrosis and inflammation in angiotensin Il-induced hypertensive cardiac disease. Hypertension 2010, 55, 953-960, doi:10.1161/HYPERTENSIONAHA.109.140608.

83. Zhang, D.; Gaussin, V.; Taffet, G.E.; Belaguli, N.S.; Yamada, M.; Schwartz, R.J.; Michael, L.H.; Overbeek, P.A.; Schneider, M.D. TAK1 is activated in the myocardium after pressure overload and is sufficient to provoke heart failure in transgenic mice. Nat Med 2000, 6, 556-563, doi:10.1038/75037.

84. Huang, H.; Tang, Q.Z.; Wang, A.B.; Chen, M.; Yan, L.; Liu, C.; Jiang, H.; Yang, Q.; Bian, Z.Y.; Bai, X.; et al. Tumor suppressor A20 protects against cardiac hypertrophy and fibrosis by blocking transforming growth factor-beta-activated kinase 1-dependent signaling. Hypertension 2010, 56, 232-239, doi:10.1161/HYPERTENSIONAHA.110.149963.

85. Laviades, C.; Varo, N.; Diez, J. Transforming growth factor beta in hypertensives with cardiorenal damage. Hypertension 2000, 36, 517522, doi:10.1161/01.hyp.36.4.517.

86. Dabek, J.; Kułach, A.; Monastyrska-Cup, B.; Gasior, Z. Transforming growth factor beta and cardiovascular diseases: the other facet of the 'protective cytokine'. Pharmacol Rep 2006, 58, 799-805.

87. Hanna, A.; Frangogiannis, N.G.J.F.i.c.m. The role of the TGF-beta superfamily in myocardial infarction. 2019, 6, 140.

88. Sanjabi, S.; Zenewicz, L.A.; Kamanaka, M.; Flavell, R.A.J.C.o.i.p. Anti-inflammatory and pro-inflammatory roles of TGF- $\beta$, IL-10, and IL22 in immunity and autoimmunity. 2009, 9, 447-453.

89. Hogan, B.L.; Blessing, M.; Winnier, G.E.; Suzuki, N.; Jones, C.M.J.D. Growth factors in development: the role of TGF- $\beta$ related polypeptide signalling molecules in embryogenesis. 1994, 1994, 53-60. 
90. de Oliveira, F.L.; Araújo-Jorge, T.C.; de Souza, E.M.; de Oliveira, G.M.; Degrave, W.M.; Feige, J.J.; Bailly, S.; Waghabi, M.C. Oral administration of GW788388, an inhibitor of transforming growth factor beta signaling, prevents heart fibrosis in Chagas disease. PLOS Negl Trop Dis 2012, 6, e1696, doi:10.1371/journal.pntd.0001696.

91. Ferreira, R.R.; Abreu, R.d.S.; Vilar-Pereira, G.; Degrave, W.; Meuser-Batista, M.; Ferreira, N.V.C.; da Cruz Moreira, O.; da Silva Gomes, N.L.; Mello de Souza, E.; Ramos, I.P.; et al. TGF- $\beta$ inhibitor therapy decreases fibrosis and stimulates cardiac improvement in a preclinical study of chronic Chagas' heart disease. PLOS Neglected Tropical Diseases 2019, 13, e0007602, doi:10.1371/journal.pntd.0007602.

92. Deten, A.; Hölzl, A.; Leicht, M.; Barth, W.; Zimmer, H.-G.J.J.o.m.; cardiology, c. Changes in extracellular matrix and in transforming growth factor beta isoforms after coronary artery ligation in rats. 2001, 33, 1191-1207.

93. Dewald, O.; Ren, G.; Duerr, G.D.; Zoerlein, M.; Klemm, C.; Gersch, C.; Tincey, S.; Michael, L.H.; Entman, M.L.; Frangogiannis, N.G.J.T.A.j.o.p. Of mice and dogs: species-specific differences in the inflammatory response following myocardial infarction. 2004, 164, 665-677.

94. Heymans, S.; Schroen, B.; Vermeersch, P.; Milting, H.; Gao, F.; Kassner, A.; Gillijns, H.; Herijgers, P.; Flameng, W.; Carmeliet, P.J.C. Increased cardiac expression of tissue inhibitor of metalloproteinase-1 and tissue inhibitor of metalloproteinase-2 is related to cardiac fibrosis and dysfunction in the chronic pressure-overloaded human heart. 2005, 112, 1136-1144.

95. Khalil, H.; Kanisicak, O.; Prasad, V.; Correll, R.N.; Fu, X.; Schips, T.; Vagnozzi, R.J.; Liu, R.; Huynh, T.; Lee, S.-J.J.T.J.o.c.i. Fibroblast-specific TGF- $\beta-S m a d 2 / 3$ signaling underlies cardiac fibrosis. 2017, 127, 3770-3783.

96. Matsumoto-Ida, M.; Takimoto, Y.; Aoyama, T.; Akao, M.; Takeda, T.; Kita, T. Activation of TGF-beta1-TAK1-p38 MAPK pathway in spared cardiomyocytes is involved in left ventricular remodeling after myocardial infarction in rats. Am J Physiol Heart Circ Physiol 2006, 290, H709-715, doi:10.1152/ajpheart.00186.2005.

97. Ellmers, L.J.; Scott, N.J.A.; Medicherla, S.; Pilbrow, A.P.; Bridgman, P.G.; Yandle, T.G.; Richards, A.M.; Protter, A.A.; Cameron, V.A. Transforming Growth Factor- $\beta$ Blockade Down-Regulates the Renin-Angiotensin System and Modifies Cardiac Remodeling after Myocardial Infarction. Endocrinology 2008, 149, 5828-5834, doi:10.1210/en.2008-0165.

98. Lotfy, M.; Adeghate, J.; Kalasz, H.; Singh, J.; Adeghate, E.J.C.d.r. Chronic complications of diabetes mellitus: a mini review. 2017, 13, 310.

99. Zhang, Y.; Cui, L.; Guan, G.; Wang, J.; Qiu, C.; Yang, T.; Guo, Y.; Liu, Z. Matrine suppresses cardiac fibrosis by inhibiting the TGF- $\beta /$ Smad pathway in experimental diabetic cardiomyopathy. Mol Med Rep 2018, 17, 1775-1781, doi:10.3892/mmr.2017.8054.

100. Chen, J.L.; Shang, Q.H.; Hu, W.; Liu, C.; Mao, W.H.; Liu, H.Q. Role of TGF- $\beta 1 / S m a d s$ pathway in carotid artery remodeling in renovascular hypertensive rats and prevention by Enalapril and Amlodipine. J Geriatr Cardiol 2012, 9, 185-191, doi:10.3724/sp.J.1263.2012.04011.

101. Peters, H.; Border, W.A.; Noble, N.A. Targeting TGF- $\beta$ overexpression in renal disease: Maximizing the antifibrotic action of angiotensin II blockade. Kidney International 1998, 54, 1570-1580, doi:https://doi.org/10.1046/i.1523-1755.1998.00164.x.

102. Yoshikawa, E.; Marui, A.; Tsukashita, M.; Nishina, T.; Wang, J.; Muranaka, H.; Ikeda, T.; Komeda, M. Carvedilol may alleviate late cardiac remodelling following surgical ventricular restoration. European Journal of Cardio-Thoracic Surgery 2010, 37, 362-367, doi:10.1016/j.ejcts.2009.04.072.

103. El-Wakeel, S.A.; Rahmo, R.M.; El-Abhar, H.S. Anti-fibrotic impact of Carvedilol in a CCl-4 model of liver fibrosis via serum microRNA200a/SMAD7 enhancement to bridle TGF-B1/EMT track. Scientific Reports 2018, 8, 14327, doi:10.1038/s41598-018-32309-1.

104. Rizvi, F.; Siddiqui, R.; DeFranco, A.; Homar, P.; Emelyanova, L.; Holmuhamedov, E.; Ross, G.; Tajik, A.J.; Jahangir, A. Simvastatin reduces TGF- $\beta 1$-induced SMAD2/3-dependent human ventricular fibroblasts differentiation: Role of protein phosphatase activation. International Journal of Cardiology 2018, 270, 228-236, doi:https://doi.org/10.1016/j.ijcard.2018.06.061.

105. Xiao, X.; Chang, G.; Liu, J.; Sun, G.; Liu, L.; Qin, S.; Zhang, D. Simvastatin ameliorates ventricular remodeling via the TGF- $\beta 1$ signaling pathway in rats following myocardial infarction. Mol Med Rep 2016, 13, 5093-5101, doi:10.3892/mmr.2016.5178. 
106. Nakanishi, N.; Kaikita, K.; Ishii, M.; Oimatsu, Y.; Mitsuse, T.; Ito, M.; Yamanaga, K.; Fujisue, K.; Kanazawa, H.; Sueta, D.; et al. Cardioprotective Effects of Rivaroxaban on Cardiac Remodeling After Experimental Myocardial Infarction in Mice. Circulation Reports 2020, 2, 158-166, doi:10.1253/circrep.CR-19-0117.

107. Jia, L.-X.; Qi, G.-M.; Liu, O.; Li, T.-T.; Yang, M.; Cui, W.; Zhang, W.-M.; Qi, Y.-F.; Du, J. Inhibition of Platelet Activation by Clopidogrel Prevents Hypertension-Induced Cardiac Inflammation and Fibrosis. Cardiovascular Drugs and Therapy 2013, 27, 521-530, doi:10.1007/s10557-013-6471-z.

108. Ma, X.-L.; Lin, Q.-Y.; Wang, L.; Xie, X.; Zhang, Y.-L.; Li, H.-H. Rituximab prevents and reverses cardiac remodeling by depressing B cell function in mice. Biomedicine \& Pharmacotherapy 2019, 114, 108804, doi:https://doi.org/10.1016/j.biopha.2019.108804.

109. Malek, V.; Gaikwad, A.B. Neprilysin inhibitors: A new hope to halt the diabetic cardiovascular and renal complications? Biomedicine \& Pharmacotherapy 2017, 90, 752-759, doi:https://doi.org/10.1016/i.biopha.2017.04.024.

110. Suematsu, Y.; Miura, S.-i.; Goto, M.; Matsuo, Y.; Arimura, T.; Kuwano, T.; Imaizumi, S.; Iwata, A.; Yahiro, E.; Saku, K. LCZ696, an angiotensin receptor-neprilysin inhibitor, improves cardiac function with the attenuation of fibrosis in heart failure with reduced ejection fraction in streptozotocin-induced diabetic mice. European Journal of Heart Failure 2016, 18, 386-393, doi:10.1002/ejhf.474.

111. Liu, G.; Liu, Y.; Wang, R.; Hou, T.; Chen, C.; Zheng, S.; Dong, Z. Spironolactone Attenuates Doxorubicin-induced Cardiotoxicity in Rats. Cardiovascular Therapeutics 2016, 34, 216-224, doi:10.1111/1755-5922.12189.

112. Luo, J.; Gao, X.; Peng, L.; Sun, H.; Dai, G. Effects of hydrochlorothiazide on cardiac remodeling in a rat model of myocardial infarctioninduced congestive heart failure. European Journal of Pharmacology 2011, 667, 314-321, doi:https://doi.org/10.1016/i.ejphar.2011.06.012.

113. Bellaye, P.-S.; Yanagihara, T.; Granton, E.; Sato, S.; Shimbori, C.; Upagupta, C.; Imani, J.; Hambly, N.; Ask, K.; Gauldie, J.; et al. Macitentan reduces progression of TGF- $\beta 1$-induced pulmonary fibrosis and pulmonary hypertension. European Respiratory Journal 2018, 52, 1701857, doi:10.1183/13993003.01857-2017.

114. Sen, S.; Chen, S.; Feng, B.; Iglarz, M.; Chakrabarti, S. Renal, retinal and cardiac changes in type 2 diabetes are attenuated by macitentan, a dual endothelin receptor antagonist. Life Sciences 2012, 91, 658-668, doi:https://doi.org/10.1016/i.lfs.2012.03.032.

115. Christensen, L.P.; Zhang, R.-I.; Zheng, W.; Campanelli, J.J.; Dedkov, E.I.; Weiss, R.M.; Tomanek, R.J. Postmyocardial infarction remodeling and coronary reserve: effects of ivabradine and beta blockade therapy. American Journal of Physiology-Heart and Circulatory Physiology 2009, 297, H322-H330, doi:10.1152/ajpheart.01337.2008.

116. Dias, P.; Navaratnarajah, M.; Alayoubi, S.; Cartledge, J.E.; Jayaratne, N.; Starke, R.; Sarathchandra, P.; Latif, N.; Randi, A.M.; Yacoub, M.H.; et al. 9 Ivabradine Alters Fibroblast Number and Transforming Growth Factor beta 1 Expression in Heart Failure. Heart 2014, 100, A4, doi:10.1136/heartjnl-2013-305297.9.

117. Kang, S.; Verma, S.; Hassanabad, A.F.; Teng, G.; Belke, D.D.; Dundas, J.A.; Guzzardi, D.G.; Svystonyuk, D.A.; Pattar, S.S.; Park, D.S.J.; et al. Direct Effects of Empagliflozin on Extracellular Matrix Remodelling in Human Cardiac Myofibroblasts: Novel Translational Clues to Explain EMPA-REG OUTCOME Results. Canadian Journal of Cardiology 2020, 36, 543-553, doi:https://doi.org/10.1016/j.cjca.2019.08.033.

118. Li, C.; Zhang, J.; Xue, M.; Li, X.; Han, F.; Liu, X.; Xu, L.; Lu, Y.; Cheng, Y.; Li, T.; et al. SGLT2 inhibition with empagliflozin attenuates myocardial oxidative stress and fibrosis in diabetic mice heart. Cardiovascular Diabetology 2019, 18, 15, doi:10.1186/s12933-019-08162.

119. Shi, Q.; Liu, X.; Bai, Y.; Cui, C.; Li, J.; Li, Y.; Hu, S.; Wei, Y. In Vitro Effects of Pirfenidone on Cardiac Fibroblasts: Proliferation, Myofibroblast Differentiation, Migration and Cytokine Secretion. PLOS ONE 2011, 6, e28134, doi:10.1371/journal.pone.0028134.

120. Yamazaki, T.; Yamashita, N.; Izumi, Y.; Nakamura, Y.; Shiota, M.; Hanatani, A.; Shimada, K.; Muro, T.; Iwao, H.; Yoshiyama, M. The antifibrotic agent pirfenidone inhibits angiotensin II-induced cardiac hypertrophy in mice. Hypertension Research 2012, 35, 34-40, doi:10.1038/hr.2011.139. 
121. Shyu, K.-G.; Wang, B.-W.; Chen, W.-J.; Kuan, P.; Hung, C.-R. Mechanism of the inhibitory effect of atorvastatin on endoglin expression induced by transforming growth factor- $\beta 1$ in cultured cardiac fibroblasts. European Journal of Heart Failure 2010, 12, 219-226, doi:10.1093/eurjhf/hfq011.

122. Kobayashi, N.; Yoshida, K.; Nakano, S.; Ohno, T.; Honda, T.; Tsubokou, Y.; Matsuoka, H. Cardioprotective Mechanisms of Eplerenone on Cardiac Performance and Remodeling in Failing Rat Hearts. Hypertension 2006, 47, 671-679, doi:10.1161/01.HYP.0000203148.42892.7a.

123. Iwamoto, M.; Hirohata, S.; Ogawa, H.; Ohtsuki, T.; Shinohata, R.; Miyoshi, T.; Hatipoglu, F.O.; Kusachi, S.; Yamamoto, K.; Ninomiya, Y. Connective tissue growth factor induction in a pressure-overloaded heart ameliorated by the angiotensin II type 1 receptor blocker olmesartan. Hypertension Research 2010, 33, 1305-1311, doi:10.1038/hr.2010.189.

124. Yamamoto, E.; Dong, Y.-F.; Kataoka, K.; Yamashita, T.; Tokutomi, Y.; Matsuba, S.; Ichijo, H.; Ogawa, H.; Kim-Mitsuyama, S. Olmesartan Prevents Cardiovascular Injury and Hepatic Steatosis in Obesity and Diabetes, Accompanied by Apoptosis Signal Regulating Kinase-1 Inhibition. Hypertension 2008, 52, 573-580, doi:10.1161/HYPERTENSIONAHA.108.112292.

125. Jin, Z.; Zhang, J.; Zhi, H.; Hong, B.; Zhang, S.; Guo, H.; Li, L. The beneficial effects of tadalafil on left ventricular dysfunction in doxorubicin-induced cardiomyopathy. Journal of Cardiology 2013, 62, 110-116, doi:https://doi.org/10.1016/j.jjcc.2013.03.018.

126. Ai, F.; Chen, M.; Yu, B.; Yang, Y.; Xu, G.; Gui, F.; Liu, Z.; Bai, X.; Chen, Z. Berberine regulates proliferation, collagen synthesis and cytokine secretion of cardiac fibroblasts via AMPK-mTOR-p70S6K signaling pathway. Int J Clin Exp Pathol 2015, 8, 12509-12516.

127. Salam, T.; El-Bakly, W.; Badawy, A.; Hasanin, A.; Raafat, M. Melatonin combination with perindopril alleviated doxorubicin cardiac toxicity in L-NAME hypertensive rats: comparative study with perindopril. Ain Shams Journal of Forensic Medicine and Clinical Toxicology 2020, 34, 69-81, doi:10.21608/ajfm.2020.68226.

128. Meurer, S.K.; Lahme, B.; Tihaa, L.; Weiskirchen, R.; Gressner, A.M. N-Acetyl-I-cysteine suppresses TGF- $\beta$ signaling at distinct molecular steps: The biochemical and biological efficacy of a multifunctional, antifibrotic drug. Biochemical Pharmacology 2005, 70, 1026-1034, doi:https://doi.org/10.1016/j.bcp.2005.07.001.

129. Talasaz, A.H.; Khalili, H.; Jenab, Y.; Salarifar, M.; Broumand, M.A.; Darabi, F. N-Acetylcysteine Effects on Transforming Growth Factor$\beta$ and Tumor Necrosis Factor- $\alpha$ Serum Levels as Pro-Fibrotic and Inflammatory Biomarkers in Patients Following ST-Segment Elevation Myocardial Infarction. Drugs in R\&D 2013, 13, 199-205, doi:10.1007/s40268-013-0025-5.

130. Leung, Y.Y.; Yao Hui, L.L.; Kraus, V.B. Colchicine-Update on mechanisms of action and therapeutic uses. Seminars in Arthritis and Rheumatism 2015, 45, 341-350, doi:https://doi.org/10.1016/j.semarthrit.2015.06.013.

131. Li, X.; Lu, Y.; Qu, C.; Zhang, E.; Tang, Y. GW26-e0768 Ticagrelor Prevents Cardiac Inflammation and Fibrosis of Hyertension Rats. Journal of the American College of Cardiology 2015, 66, C268, doi:10.1016/j.jacc.2015.06.1041.

132. Sui, X.; Wei, H.; Wang, D. Novel mechanism of cardiac protection by valsartan: synergetic roles of TGF- $\beta 1$ and HIF-1 $\alpha$ in Ang II-mediated fibrosis after myocardial infarction. J Cell Mol Med 2015, 19, 1773-1782, doi:10.1111/jcmm.12551.

133. Xiao, H.; Ma, X.; Feng, W.; Fu, Y.; Lu, Z.; Xu, M.; Shen, Q.; Zhu, Y.; Zhang, Y. Metformin attenuates cardiac fibrosis by inhibiting the TGFB1-Smad3 signalling pathway. Cardiovascular Research 2010, 87, 504-513, doi:10.1093/cvr/cvq066.

134. Sonoda, K.; Ohtake, K.; Uchida, H.; Ito, J.; Uchida, M.; Natsume, H.; Tamada, H.; Kobayashi, J. Dietary nitrite supplementation attenuates cardiac remodeling in I-NAME-induced hypertensive rats. Nitric Oxide 2017, 67, 1-9, doi:https://doi.org/10.1016/j.niox.2017.04.009.

135. Ceron, C.S.; Rizzi, E.; Guimarães, D.A.; Martins-Oliveira, A.; Gerlach, R.F.; Tanus-Santos, J.E. Nebivolol attenuates prooxidant and profibrotic mechanisms involving TGF- $\beta$ and MMPs, and decreases vascular remodeling in renovascular hypertension. Free Radical Biology and Medicine 2013, 65, 47-56, doi:https://doi.org/10.1016/j.freeradbiomed.2013.06.033.

136. Rai, N.; Veeroju, S.; Schymura, Y.; Janssen, W.; Wietelmann, A.; Kojonazarov, B.; Weissmann, N.; Stasch, J.-P.; Ghofrani, H.A.; Seeger, W.; et al. Effect of Riociguat and Sildenafil on Right Heart Remodeling and Function in Pressure Overload Induced Model of Pulmonary Arterial Banding. BioMed Research International 2018, 2018, 3293584, doi:10.1155/2018/3293584. 
137. Ding, M.-J.; Su, K.; Cui, G.Z.; Yang, W.H.; Chen, L.; Yang, M.; Liu, Y.-Q.; Dai, D.-L.J.O.I. Association between transforming growth factor$\beta 1$ expression and the clinical features of triple negative breast cancer. 2016, 11, 4040-4044.

138. Calon, A.; Espinet, E.; Palomo-Ponce, S.; Tauriello, D.V.; Iglesias, M.; Céspedes, M.V.; Sevillano, M.; Nadal, C.; Jung, P.; Zhang, X.H.F.J.C.c. Dependency of colorectal cancer on a TGF- $\beta$-driven program in stromal cells for metastasis initiation. 2012, 22, 571-584.

139. Yokouchi, H.; Nishihara, H.; Harada, T.; Ishida, T.; Yamazaki, S.; Kikuchi, H.; Oizumi, S.; Uramoto, H.; Tanaka, F.; Harada, M.J.O. Immunohistochemical profiling of receptor tyrosine kinases, MED12, and TGF- $\beta$ RII of surgically resected small cell lung cancer, and the potential of c-kit as a prognostic marker. 2017, 8, 39711.

140. Cerami, E.; Gao, J.; Dogrusoz, U.; Gross, B.E.; Sumer, S.O.; Aksoy, B.A.; Jacobsen, A.; Byrne, C.J.; Heuer, M.L.; Larsson, E. The cBio cancer genomics portal: an open platform for exploring multidimensional cancer genomics data. 2012.

141. Gao, J.; Aksoy, B.A.; Dogrusoz, U.; Dresdner, G.; Gross, B.; Sumer, S.O.; Sun, Y.; Jacobsen, A.; Sinha, R.; Larsson, E.J.S.s. Integrative analysis of complex cancer genomics and clinical profiles using the cBioPortal. 2013, 6, pl1-pl1.

142. Sulaiman, A.; McGarry, S.; Chilumula, S.C.; Kandunuri, R.; Vinod, V.J.B. Clinically Translatable Approaches of Inhibiting TGF- $\beta$ to Target Cancer Stem Cells in TNBC. 2021, 9, 1386.

143. Pang, M.; Georgoudaki, A.; Lambut, L.; Johansson, J.; Tabor, V.; Hagikura, K.; Jin, Y.; Jansson, M.; Alexander, J.; Nelson, C.M.J.O. TGF$\beta 1$-induced EMT promotes targeted migration of breast cancer cells through the lymphatic system by the activation of CCR7/CCL21mediated chemotaxis. 2016, 35, 748-760.

144. Nie, Z.; Wang, C.; Zhou, Z.; Chen, C.; Liu, R.; Wang, D.J.A.b.e.b.S. Transforming growth factor-beta increases breast cancer stem cell population partially through upregulating PMEPA1 expression. 2016, 48, 194-201.

145. Bhola, N.E.; Balko, J.M.; Dugger, T.C.; Kuba, M.G.; Sánchez, V.; Sanders, M.; Stanford, J.; Cook, R.S.; Arteaga, C.L.J.T.J.o.c.i. TGF- $\beta$ inhibition enhances chemotherapy action against triple-negative breast cancer. 2013, 123, 1348-1358.

146. Buck, M.B.; Fritz, P.; Dippon, J.; Zugmaier, G.; Knabbe, C.J.C.C.R. Prognostic significance of transforming growth factor $\beta$ receptor II in estrogen receptor-negative breast cancer patients. 2004, 10, 491-498.

147. Phi, L.T.H.; Sari, I.N.; Yang, Y.-G.; Lee, S.-H.; Jun, N.; Kim, K.S.; Lee, Y.K.; Kwon, H.Y.J.S.c.i. Cancer stem cells (CSCs) in drug resistance and their therapeutic implications in cancer treatment. 2018, 2018.

148. Aleksakhina, S.N.; Kashyap, A.; Imyanitov, E.N.J.B.e.B.A.-R.o.C. Mechanisms of acquired tumor drug resistance. 2019, $1872,188310$.

149. Murayama, T.; Gotoh, N.J.C.D.R. Drug resistance mechanisms of cancer stem-like cells and their therapeutic potential as drug targets. 2019, 2, 457-470.

150. Al-Hajj, M.; Wicha, M.S.; Benito-Hernandez, A.; Morrison, S.J.; Clarke, M.F.J.P.o.t.N.A.o.S. Prospective identification of tumorigenic breast cancer cells. 2003, 100, 3983-3988.

151. Sulaiman, A.; McGarry, S.; Li, L.; Jia, D.; Ooi, S.; Addison, C.; Dimitroulakos, J.; Arnaout, A.; Nessim, C.; Yao, Z.J.M.o. Dual inhibition of Wnt and Yes-associated protein signaling retards the growth of triple-negative breast cancer in both mesenchymal and epithelial states. 2018, 12, 423-440.

152. Sulaiman, A.; Yao, Z.; Wang, L.J.J.o.b.r. Re-evaluating the role of epithelial-mesenchymal-transition in cancer progression. $2018,32,81$.

153. Fontana, F.; Raimondi, M.; Marzagalli, M.; Sommariva, M.; Limonta, P.; Gagliano, N.J.C. Epithelial-to-mesenchymal transition markers and CD44 isoforms are differently expressed in 2D and 3D cell cultures of prostate cancer cells. 2019, 8, 143.

154. Liu, S.; Cong, Y.; Wang, D.; Sun, Y.; Deng, L.; Liu, Y.; Martin-Trevino, R.; Shang, L.; McDermott, S.P.; Landis, M.D.J.S.c.r. Breast cancer stem cells transition between epithelial and mesenchymal states reflective of their normal counterparts. 2014, 2, 78-91.

155. Vikram, R.; Chou, W.C.; Hung, S.-C.; Shen, C.-Y.J.C. Tumorigenic and Metastatic Role of CD44-/low/CD24-/low Cells in Luminal Breast Cancer. 2020, 12, 1239.

156. Ginestier, C.; Hur, M.H.; Charafe-Jauffret, E.; Monville, F.; Dutcher, J.; Brown, M.; Jacquemier, J.; Viens, P.; Kleer, C.G.; Liu, S.J.C.s.c. ALDH1 is a marker of normal and malignant human mammary stem cells and a predictor of poor clinical outcome. 2007, 1, 555-567. 
157. Jia, D.; Li, L.; Andrew, S.; Allan, D.; Li, X.; Lee, J.; Ji, G.; Yao, Z.; Gadde, S.; Figeys, D.J.C.d.; et al. An autocrine inflammatory forwardfeedback loop after chemotherapy withdrawal facilitates the repopulation of drug-resistant breast cancer cells. 2017, 8, e2932-e2932.

158. Han, J.; Lim, W.; You, D.; Jeong, Y.; Kim, S.; Lee, J.E.; Shin, T.H.; Lee, G.; Park, S.J.J.o.o. Chemoresistance in the human triple-negative breast cancer cell line MDA-MB-231 induced by doxorubicin gradient is associated with epigenetic alterations in histone deacetylase. 2019, 2019.

159. Xu, X.; Zhang, L.; He, X.; Zhang, P.; Sun, C.; Xu, X.; Lu, Y.; Li, F.J.B.; communications, b.r. TGF- $\beta$ plays a vital role in triple-negative breast cancer (TNBC) drug-resistance through regulating stemness, EMT and apoptosis. 2018, 502, 160-165.

160. Asiedu, M.K.; Ingle, J.N.; Behrens, M.D.; Radisky, D.C.; Knutson, K.L.J.C.r. TGFB/TNFa-mediated epithelial-mesenchymal transition generates breast cancer stem cells with a claudin-low phenotype. 2011, 71, 4707-4719.

161. Zhang, M.; Wu, J.; Mao, K.; Deng, H.; Yang, Y.; Zhou, E.; Liu, J.J.I.J.o.S. Role of transforming growth factor- $\beta 1$ in triple negative breast cancer patients. 2017, 45, 72-76.

162. Lu, S.; Dong, Z.J.T.P. Characterization of TGF- $\beta$-regulated interleukin-8 expression in human prostate cancer cells. 2006, 66, 996-1004.

163. Bates, R.C.; DeLeo III, M.J.; Mercurio, A.M.J.E.C.r. The epithelial-mesenchymal transition of colon carcinoma involves expression of IL8 and CXCR-1-mediated chemotaxis. 2004, 299, 315-324.

164. Jia, D.; Tan, Y.; Liu, H.; Ooi, S.; Li, L.; Wright, K.; Bennett, S.; Addison, C.L.; Wang, L.J.O. Cardamonin reduces chemotherapy-enriched breast cancer stem-like cells in vitro and in vivo. 2016, 7, 771.

165. Samanta, D.; Gilkes, D.M.; Chaturvedi, P.; Xiang, L.; Semenza, G.L.J.P.o.t.N.A.o.S. Hypoxia-inducible factors are required for chemotherapy resistance of breast cancer stem cells. 2014, 111, E5429-E5438.

166. Zhuang, X.; Wang, J.J.J.B. Correlations of MRP1 gene with serum TGF-beta 1 and IL-8 in breast cancer patients during chemotherapy. 2018, 23, 1302-1308.

167. Ignacio, R.M.C.; Gibbs, C.R.; Lee, E.-S.; Son, D.-S.J.O. The TGFa-EGFR-Akt signaling axis plays a role in enhancing proinflammatory chemokines in triple-negative breast cancer cells. 2018, 9, 29286.

168. Smith, B.N.; Burton, L.J.; Henderson, V.; Randle, D.D.; Morton, D.J.; Smith, B.A.; Taliaferro-Smith, L.; Nagappan, P.; Yates, C.; Zayzafoon, M.J.P.o. Snail promotes epithelial mesenchymal transition in breast cancer cells in part via activation of nuclear ERK2. 2014,9 , e104987.

169. Liu, F.; Gu, L.N.; Shan, B.E.; Geng, C.Z.; Sang, M.X.J.O.I. Biomarkers for EMT and MET in breast cancer: An update. 2016, 12, 4869-4876.

170. Park, S.-Y.; Kim, M.-J.; Park, S.-A.; Kim, J.-S.; Min, K.-N.; Kim, D.-K.; Lim, W.; Nam, J.-S.; Sheen, Y.Y.J.O. Combinatorial TGF- $\beta$ attenuation with paclitaxel inhibits the epithelial-to-mesenchymal transition and breast cancer stem-like cells. 2015, 6, 37526.

171. Wardhani, B.W.; Puteri, M.U.; Watanabe, Y.; Louisa, M.; Setiabudy, R.; Kato, M.J.J.o.E.P. TGF- $\beta$-Induced TMEPAI Attenuates the Response of Triple-Negative Breast Cancer Cells to Doxorubicin and Paclitaxel. 2020, 12, 17.

172. Singha, P.K.; Yeh, I.-T.; Venkatachalam, M.A.; Saikumar, P.J.C.r. Transforming growth factor- $\beta$ (TGF- $\beta$ )-inducible gene TMEPAI converts TGF- $\beta$ from a tumor suppressor to a tumor promoter in breast cancer. 2010, 70, 6377-6383.

173. Zhang, J.; Chen, Y.-L.; Ji, G.; Fang, W.; Gao, Z.; Liu, Y.; Wang, J.; Ding, X.; Gao, F. Sorafenib Inhibits Epithelial-Mesenchymal Transition through an Epigenetic-Based Mechanism in Human Lung Epithelial Cells. PLOS ONE 2013, 8, e64954, doi:10.1371/journal.pone.0064954.

174. Wang, Q.; Yu, T.; Yuan, Y.; Zhuang, H.; Wang, Z.; Liu, X.; Feng, M. Sorafenib reduces hepatic infiltrated regulatory T cells in hepatocellular carcinoma patients by suppressing TGF-beta signal. Journal of Surgical Oncology 2013, 107, 422-427, doi:10.1002/jso.23227.

175. Yoshida, T.; Ozawa, Y.; Kimura, T.; Sato, Y.; Kuznetsov, G.; Xu, S.; Uesugi, M.; Agoulnik, S.; Taylor, N.; Funahashi, Y.; et al. Eribulin mesilate suppresses experimental metastasis of breast cancer cells by reversing phenotype from epithelial-mesenchymal transition (EMT) to mesenchymal-epithelial transition (MET) states. British Journal of Cancer 2014, 110, 1497-1505, doi:10.1038/bjc.2014.80.

176. Cortes, J.; Schöffski, P.; Littlefield, B.A. Multiple modes of action of eribulin mesylate: Emerging data and clinical implications. Cancer Treatment Reviews 2018, 70, 190-198, doi:https://doi.org/10.1016/i.ctrv.2018.08.008.

177. Kudo, M. Pembrolizumab for the Treatment of Hepatocellular Carcinoma. Liver Cancer 2019, 8, 143-154, doi:10.1159/000500143. 
178. Liu, Z.; Li, X.; He, X.; Xu, Y.; Wang, X. Complete response to the combination of Lenvatinib and Pembrolizumab in an advanced hepatocellular carcinoma patient: a case report. BMC Cancer 2019, 19, 1062, doi:10.1186/s12885-019-6287-8.

179. Qiu, H.; Li, J.; Liu, Q.; Tang, M.; Wang, Y. Apatinib, a novel tyrosine kinase inhibitor, suppresses tumor growth in cervical cancer and synergizes with Paclitaxel. Cell Cycle 2018, 17, 1235-1244, doi:10.1080/15384101.2018.1471315.

180. Strongman, H.; Gadd, S.; Matthews, A.; Mansfield, K.E.; Stanway, S.; Lyon, A.R.; dos-Santos-Silva, I.; Smeeth, L.; Bhaskaran, K.J.T.L. Medium and long-term risks of specific cardiovascular diseases in survivors of 20 adult cancers: a population-based cohort study using multiple linked UK electronic health records databases. 2019, 394, 1041-1054. 